\title{
Response of Broccoli Transplants to LED Light during Short and Long-Term Storage
}

\author{
Renata Wojciechowska ${ }^{1}$, Edward Kunicki ${ }^{1}$, Olga Długosz-Grochowska ${ }^{2}{ }^{(0)}$ and \\ Anna Kołton 1,*(1) \\ 1 Faculty of Biotechnology and Horticulture, University of Agriculture in Krakow, 29 Listopada 54, \\ 31-425 Krakow, Poland; renata.wojciechowska@urk.edu.pl (R.W.); edward.kunicki@urk.edu.pl (E.K.) \\ 2 Malopolska Centre of Biotechnology, Jagiellonian University, Gronostajowa 7A, 30-387 Kraków, Poland; \\ olga.dlugosz-grochowska@uj.edu.pl \\ * Correspondence: anna.kolton@urk.edu.pl
}

Received: 8 June 2020; Accepted: 10 July 2020; Published: 14 July 2020

\begin{abstract}
In broccoli production a big challenge is preparation of seedlings, which must be delivered during a strictly defined period to vegetable producers that are often in distant places. The goal of the present study was to investigate the response of 5-week old broccoli transplants $\mathrm{cv}$. Parthenon $\mathrm{F}_{1}$ to 2 and 6 weeks of storage at $4{ }^{\circ} \mathrm{C}$ under two LED light spectra (L1: 29\% red $660 \mathrm{~nm}+14 \%$ red $630 \mathrm{~nm}+42 \%$ blue $250 \mathrm{~nm}+15 \%$ green $520 \mathrm{~nm}$ and $\mathrm{L} 2: 38 \%$ red $660 \mathrm{~nm}+18 \%$ red $630 \mathrm{~nm}+26 \%$ blue $450 \mathrm{~nm}+15 \%$ green $520 \mathrm{~nm}+3 \%$ UV-A $330 \mathrm{~nm}$; photoperiod 16/8 h day/night and PPFD $30 \pm 10 \mu \mathrm{mol}$ $\mathrm{m}^{-2} \mathrm{~s}^{-1}$ ) and darkness. Control 5-week-old seedlings were not stored. Light treatment improved the morphology and physiological parameters of seedlings. The yield of broccoli from control seedlings was similar to that obtained after L2 treatment, regardless of seedling storage duration. The most promising effects were obtained by adding $3 \%$ UV-A radiation to the lighting spectrum. The results are applicable to the transport of broccoli transplants to remote locations or storage for several weeks, in cases where it is necessary to delay planting.
\end{abstract}

Keywords: UV-A; growth parameters; dry matter; soluble sugars; total proteins; phenols; MDA; photosynthetic pigments; chlorophyll fluorescence; broccoli yield

\section{Introduction}

On a global scale, broccoli (Brassica oleracea L. var. italica Plenck) belongs to a group of vegetables of great economic importance. The production of cauliflower and broccoli in Poland represented 1.1\% of the total world production in 2018. This gave Poland a place among the leading producers in Europe, with Spain leading the way. The consumption per person is growing steadily [1,2]. Broccoli owes its growing popularity to the fact that it is a rich source of health promoting compounds, showing high radical scavenging activity [3-5] and potential anti-cancer properties [6,7].

Depending on climate conditions and weather, broccoli can be directly seeded or transplanted. Primarily, in certain regions, broccoli is grown from transplants, using seedlings with 4-6 developed leaves at the time of transplanting. Broccoli seedlings are most often offered by producers at this growth stage. A big challenge for them is the rapidly growing demand for broccoli seedlings, which must be delivered to vegetable producers during a strictly defined period, often to very distant places. In such cases, seedling producers would benefit from a system that would allow plants to be transported for as long as possible without the risk of losing their quality parameters. Additionally, vegetable producers are often unable to transplant seedlings during the scheduled time due to various reasons, e.g., adverse weather, lack of proper equipment, problems with labor force. The solution to this problem would be a meticulously designed plant storage system [8]. Therefore, the question is whether seedlings can be 
transported and/or stored with the use of a system - that is designed to maintain the proper storage conditions and simultaneously do not require a large energy input to function. In the last few decades, many research studies have been conducted on the storage of vegetable seedlings at low temperatures, which inhibits the growth of plants, but also allows the preservation of good quality seedlings and high yield of good quality $[9,10]$. Research has focused on optimizing the environment in terms of photoperiod, light intensity, and spectral quality as well as the composition of the gaseous atmosphere $\left(\mathrm{CO}_{2}\right.$ and $\mathrm{O}_{2}$ concentrations), which, combined with the right storage temperature, can improve the ability to store seedlings without causing deterioration [11].

For economic reasons, the easiest solution would be to keep the seedlings in the dark, at moderate temperature. Results obtained on cabbage (Brassica oleracea L. var. capitata L.) seedlings showed that plants stored at $15^{\circ} \mathrm{C}$ for 2 weeks continued to grow, but resulted in weakening of the plants and caused difficulties for continuing normal growth in the field after storage [12]. In addition, Sato et al. [13] found that elongation growth of cabbage seedlings occurs at a temperature range from 5 to $10^{\circ} \mathrm{C}$. Whereas Grabowska et al. [14] showed the possibility of storing broccoli seedlings in the dark at $2{ }^{\circ} \mathrm{C}$ for 2 weeks, without loss of crop-forming potential. However, some in vitro studies suggested a negative influence of storing broccoli seedlings in the dark at $5{ }^{\circ} \mathrm{C}$ for 4 weeks, resulting in reduced quality of plants and re-growth potential [15]. Seedling illumination during storage was necessary to maintain good quality of cabbage seedlings, with red light providing better results than white or blue light emitting diodes (LEDs) [16]. In cited research, $60 \mathrm{~min}$ of red light illumination per day was effective at suppressing shoot elongation and maintaining the photosynthetic ability of cold-stored $\left(10^{\circ} \mathrm{C}\right)$ seedlings. However, it should be emphasized that there are few studies concerning vegetable transplants stored under LED light. Available research is concentrated on the effects of LED irradiance during seedlings growth; both in closed environment chambers and in greenhouses (as supplemental lighting) $[17,18]$. Moreover, few works are focused on broccoli seedlings under LED light [19]. Most studies showed the beneficial effects of red light $(670-700 \mathrm{~nm})$ combined with blue light $(425-490 \mathrm{~nm})$ on seedling quality but the proper ratio of red to blue light seems to be species/cultivar specific and may vary depending on environment factors and cultivation methods. Blue light proves to be beneficial, primarily in enhancing the synthesis of chlorophylls or phenolic compounds and in decreasing plant height while simultaneously increasing dry matter [20]. Some research has also included green light $(490-550 \mathrm{~nm})$ into the red and blue spectrum for, e.g., cherry tomato (Solanum lycopersicum L.) seedling [21] and lettuce (Lactuca sativa L.) [22] cultivation, but the effects are not consistent. Samuoliene et al. [23] showed that green light can beneficially modify photosynthesis and growth parameters of cucumber (Cucumis sativus), tomato, and sweet pepper (Capsicum annuum L.) transplants.

In the last decade, more attention has been paid to the effect of LED light on the postharvest maintenance of quality of many horticultural products and some works were carried out on broccoli [24]. For example, low intensity of white and blue LED light $\left(20 \mu \mathrm{mol} \mathrm{m} \mathrm{m}^{-2} \mathrm{~s}^{-1}\right.$ PPFD) resulted in an increase of chlorophylls and soluble sugars in broccoli heads compared to a control in the dark [25]. The effects of light on leaf senescence of perishable vegetables in the postharvest stage have also been studied. For example, warm white LED light at a low intensity effectively inhibited the senescence of lamb's lettuce (Valerianella locusta Laterrem. Betcke) compared to storage in the dark [26]. Generally, in postharvest treatments of leafy vegetables, the light intensity used for treatments did not exceed $30 \mu \mathrm{mol} \mathrm{m} \mathrm{m}^{-2} \mathrm{~s}^{-1}$ PPFD [24]. Cited studies indicate that energy-efficient LED lamps with an appropriate emitting spectrum could be successfully used to illuminate fully-developed broccoli transplants during storage. Notably, glass covering a greenhouse filters out ultraviolet radiation, so plants grown in such conditions may present with a lack of adaptation to UV light $(290-400 \mathrm{~nm})$ [27]. Transferring plants into the dark for several weeks, additionally exposes plants to light stress. This stress may occur just after transplanting into the natural environment due to sunburn, especially that caused by UV-B (290-315 nm). Štroch et al. [28] revealed that exposure to UV-A radiation effectively eliminated the negative effect of UV-B radiation and increased resistance of the photosynthetic apparatus of barley (Hordeum vulgare L.) against UV-B. 
The purpose of this study was to investigate the effect of two light spectra (one with more blue and a second enriched with UV-A) and storage time of 5-week-old broccoli transplants at low temperatures on their morphological, physiological, and chemical parameters. The main hypothesis, which has been verified in the presented study, was that 5-week-old broccoli transplants stored at $4{ }^{\circ} \mathrm{C}$ for 2 and 6 weeks with provided LED illumination would maintain quality parameters comparable to those before storage, and that a temperature of $4{ }^{\circ} \mathrm{C}$ would stop the growth of treated plants. Moreover, we hypothesized that the morphological and biochemical parameters of broccoli transplants illuminated with different LED light spectra would be positively affected and that keeping transplants in the aforementioned conditions would have no negative effects on the crop-forming potential. The obtained results can be used as a guideline for seedling growers to manage the LED light environment needed to transport broccoli transplants to remote locations or storage for several weeks, in cases where it is necessary to delay planting.

\section{Materials and Methods}

\subsection{Plant Material and Growth Conditions}

Broccoli (Brassica oleracea var. italica Plenck) cv. Parthenon $\mathrm{F}_{1}$ was used in the experiment. The study was carried out in 2019 at the University of Agriculture in Krakow (Poland): In the greenhouse (production of broccoli transplants) and in closed chambers (transplant storage). Two storage durations were established: 2 weeks (short term) and 6 weeks (long term). In both cases, seedlings were put into the chamber at the same age (5-weeks-old). During storage, plants were treated with two kinds of LED light (L1 and L2; explanation below). The end date for all combinations was 1 July when broccoli transplants were planted into the field at the Experimental Station (50 $\left.5^{\prime} 1^{\prime \prime} \mathrm{N}, 19^{\circ} 51^{\prime} 32^{\prime \prime} \mathrm{E}\right)$. Control (not stored, 5-week-old seedlings grown in the greenhouse) were planted together with stored plants into the experimental plots at $75 \times 40 \mathrm{~cm}$ spacing. Agronomic treatments were applied in accordance with the requirements of the species. All dates of important cultivation terms are presented in Table 1 . This table also includes the treatment symbols used in the text.

Table 1. Important dates in broccoli cultivation and treatment designations used in the text.

\begin{tabular}{|c|c|c|c|c|c|}
\hline $\begin{array}{l}\text { Date of } \\
\text { Sowing }\end{array}$ & $\begin{array}{l}\text { Plant Age in } \\
\text { Weeks before } \\
\text { Storage }\end{array}$ & $\begin{array}{c}\text { Term T0 before } 2 \\
\text { or } 6 \text { Weeks of } \\
\text { Storage or } \\
\text { without Storage }\end{array}$ & $\begin{array}{l}\text { Storage } \\
\text { Duration in } \\
\text { Weeks }\end{array}$ & $\begin{array}{c}\text { Term T1 after } \\
\text { Storage in } \\
\text { Darkness (D) and } \\
\text { under LED Light: } \\
\text { L1 or L2 }\end{array}$ & $\begin{array}{l}\text { Age of Plants } \\
\text { Planted on 1st } \\
\text { July in Weeks }\end{array}$ \\
\hline 15 April & 5 & $\begin{array}{c}20 \text { May } \\
\text { T0(6) }\end{array}$ & 6 & $\begin{array}{c}1 \text { July } \\
\text { T1-6D; T1-6L1; } \\
\text { T1-6L2 }\end{array}$ & 11 \\
\hline 13 May & 5 & $\begin{array}{l}17 \text { June } \\
\mathrm{T} 0(2)\end{array}$ & 2 & $\begin{array}{c}1 \text { July } \\
\text { T1-2D; T1-2L1; } \\
\text { T1-2L2 }\end{array}$ & 7 \\
\hline 27 May & 5 & $\begin{array}{c}1 \text { July } \\
\text { T0 }\end{array}$ & 0 & $\cos 2 \cos 20$ & 5 \\
\hline
\end{tabular}

Seeds of broccoli "Parthenon $\mathrm{F}_{1}$ "were sown individually into 96 cell multi-pots $(60 \times 40 \mathrm{~cm})$ with a volume of $0.053 \mathrm{dm}^{3}$ each ( 400 plants per $\mathrm{m}^{2}$ ) and germinated in a peat substrate Florabalt Seed (Floragard Product) ( $\mathrm{pH} 5.6 ; \mathrm{N} 140, \mathrm{P}_{2} \mathrm{O}_{5}$ 80, and $\mathrm{K}_{2} \mathrm{O} 190 \mathrm{mg} \mathrm{L}^{-1}$ ). After the formation of a second pair of true leaves, seedlings were fertilized twice with a water solution of Kristalon Green Yara $18+18+18(\mathrm{~N}-18 \%$, P-18\%, K-18\%, Mg-3\%, S-5\%, B-0.025\%, Cu-0.01\%, Fe-0.07\%, Mn-0.04\%, Mo-0.004\%, Zn-0.025\%) fertilizer at a concentration of $0.1 \%$.

Until storage, plants were grown with a natural photoperiod in the greenhouse $\left(50^{\circ} 03^{\prime} \mathrm{N}, 19^{\circ} 57^{\prime} \mathrm{E}\right)$. Environmental conditions in the greenhouse during broccoli growth are presented in Table 2. 
Table 2. Environmental conditions during which transplants were grown in the greenhouse.

\begin{tabular}{cccccc}
\hline Period & $\begin{array}{c}\text { Mean Temperature } \\
\left({ }^{\circ} \mathbf{C}\right) \pm \mathbf{2}\end{array}$ & $\begin{array}{c}\text { Mean Relative Humidity } \\
(\mathbf{\%} \mathbf{C} \mathbf{2} \mathbf{\%}\end{array}$ & $\begin{array}{c}\text { Solar Radiation } \\
\mathbf{J ~ c m}^{\mathbf{2}} \\
\text { Mean per Day }\end{array}$ \\
\hline 15 April-20 May & Day & Night & Day & Night & \\
13 May-17 June & 30 & 18 & 41 & 54 & 1208 \\
27 May-1 July & 33 & 22 & 45 & 61 & 1546 \\
\hline
\end{tabular}

\subsection{Light Conditions during Storage}

The 5-week-old "Parthenon $\mathrm{F}_{1}$ " broccoli transplants cultivated in the greenhouse were transferred to the closed chamber with a temperature of $4{ }^{\circ} \mathrm{C}$ and relative humidity of $65 \% \pm 2 \%$. Three combinations of light conditions were established: storage in darkness (D) and two in light under two kinds of LED lamps emitting various spectra (percentage share in spectrum, color, and wavelength: L1 $29 \%$ red $660 \mathrm{~nm}+$ $14 \%$ red $630 \mathrm{~nm}+42 \%$ blue $250 \mathrm{~nm}+15 \%$ green $520 \mathrm{~nm}$ ) and L2(38\% red $660 \mathrm{~nm}+18 \%$ red $630 \mathrm{~nm}$ $+26 \%$ blue $450 \mathrm{~nm}+15 \%$ green $520 \mathrm{~nm}+3 \%$ UV-A $330 \mathrm{~nm})$ ). Each light treatment consisted of two identical lamps $(100 \times 8 \times 7 \mathrm{~cm})$ that were separated from each other by curtains. Lamps were made by Growlux Michał Król company specially for our purposes, spectral composition was designed by our team. Spectral characteristics of the lamps used are shown in Figure 1. The photoperiod was set at 16/8 h day/night and the photosynthetic photon flux density (PPFD) reaching the plants under all lamps was $30 \pm 10 \mu \mathrm{mol} \mathrm{m}{ }^{-2} \mathrm{~s}^{-1}$. Broccoli transplants were stored in either light combination or darkness (in total 192 transplants for each storage duration, i.e., 2 and 6 weeks).

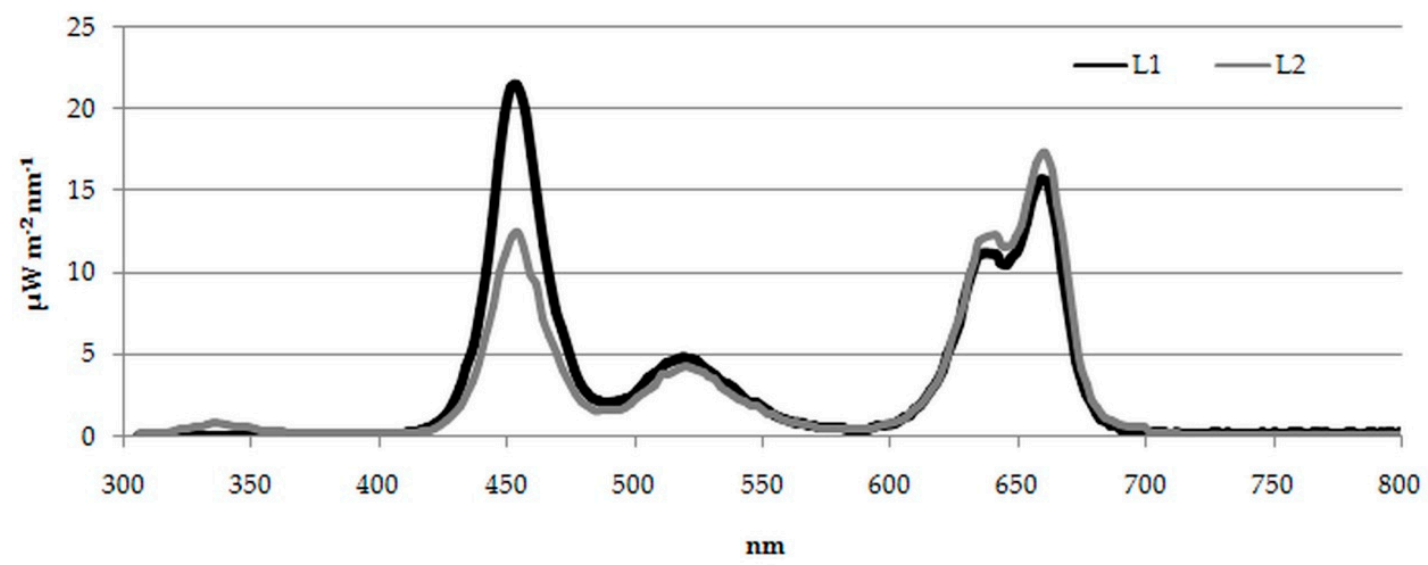

Figure 1. Spectral characteristics of the light emitting diode (LED) lamps, measured using SpectraPen mini (Photon Systems Instruments, Drásov, Czech Republic) after dark calibration.

\subsection{Growth Analyses}

Twenty randomly chosen plants from each treatment were harvested to perform the following measurements: Stem length (from the substrate surface to the apical meristem, using a ruler), stem diameter (using electronic caliper), leaf number, and leaf area, measured with a system for leaf surface analysis (WinDIAS, UK).

\subsection{Chemical Analyses}

Twenty randomly selected leaves (fully developed second or third leaf from the apex) of each treatment were harvested for chemical analyses. All chemical analyses were performed in four laboratory replications for each treatment.

Dry matter content (\%) of leaves was estimated by drying $1 \mathrm{~g}$ of shredded fresh material at $105^{\circ} \mathrm{C}$. The samples were dried to determine the constant weight (about three hours). 
Soluble sugars content was evaluated using the colorimetric method described by Yemm and Wills [29]. The optical density of plant ethanol extracts after reaction with the anthrone reagent were measured at $625 \mathrm{~nm}$ on a spectrophotometer Helios Beta (Thermo Fisher Scientific Inc., Bartlesville, OK, USA). The content of soluble sugars was calculated according to the calibration curve of glucose as a standard.

For total protein content estimation, fresh material was ground with liquid nitrogen and stored at $-36^{\circ} \mathrm{C}$. Total protein was extracted from frozen tissue with cold phosphate buffer $(0.05 \mathrm{M}, \mathrm{pH} 7.5)$ with the addition of $1 \mathrm{mM}$ PMSF (phenylmethylsulfonyl fluoride, Sigma) and $1 \mathrm{mM}$ DTT (dithiothreitol, Sigma). After centrifugation (7000 rpm, $30 \mathrm{~min}, 4^{\circ} \mathrm{C}$, centrifuge Hettich Rotina 380R, Tuttlingen, Germany), the supernatant was collected and used for reaction with the Bradford reagent [30]. Absorption was read at $595 \mathrm{~nm}$ (UV-VIS spectrophotometer, Hitachi U-2900, Tokyo, Japan). A standard curve was prepared with bovine albumin (Sigma). The results were calculated in $\mathrm{mg}$ of protein per $100 \mathrm{~g}$ of fresh material.

Photosynthetic pigments were extracted in $80 \%$ acetone and the absorbance reading was carried out at 470,646 , and $663 \mathrm{~nm}$ wavelengths. The procedure and calculations were performed as described by Lichtenthaler and Wellburn [31]. Pheophytin content was estimated spectrophotometrically (at 665 and $750 \mathrm{~nm}$ ) and calculated according to Axler and Owen [32].

Total phenol content was determined in $80 \%$ methanol extracts using Folin-Ciocalteu reagent [33] and absorbance was detected at $740 \mathrm{~nm}$. A calibration curve was calculated using gallic acid as a standard.

Lipid oxidation analysis involved the thiobarbituric acid (TBA, Sigma) reaction with malondialdehyde (MDA). Frozen plant material was extracted with $80 \%$ ethanol containing $0.1 \%$ trichloroacetic acid (TCA, Sigma). After centrifugation ( $5000 \mathrm{rpm}, 15 \mathrm{~min} 4{ }^{\circ} \mathrm{C}$, centrifuge Hettich Rotina 380R, Tuttlingen, Germany), the supernatant aliquot was mixed with a solution of $20 \%$ TCA with $0.65 \%$ TBA and heated at $95{ }^{\circ} \mathrm{C}$ for $25 \mathrm{~min}$. After cooling and centrifugation, the absorbance measurement was made at 440, 532, and $600 \mathrm{~nm}$ (UV-VIS spectrophotometer Hitachi U-2900, Tokyo, Japan) according to Du and Bramlage [34]. The value of molar extinction coefficient of MDA was assumed at 157,000. The results were calculated in nmol of MDA per $1 \mathrm{~g}$ of fresh material.

\subsection{Chlorophyll Fluorescence Analyses}

Chlorophyll a fluorescence measurement was made on the leaves of broccoli seedlings with a HandyPea meter (Hansatech, King's Lynn, UK). At least 10 leaves from each treatment were evaluated. After dark adaptation ( $30 \mathrm{~min}$ ) with leaf clips, the analysis was made after flash-light treatment with $3500 \mu \mathrm{mol} \mathrm{m}{ }^{-2} \mathrm{~s}^{-1}$ intensity. The JIP-test parameters were calculated with formulas from Stirbet et al. [35]. The ratio of $\mathrm{Fv} / \mathrm{Fm}$ describes the maximum quantum yield of PSII photochemistry that leads to primary PSII acceptor $(\mathrm{QA})$ reduction, and $\mathrm{Fv} / \mathrm{F}_{0}$ is the ratio of maximum photochemical and non-photochemical processes in PSII, which is a very sensitive indicator of the efficiency of photochemical processes in PSII. The parameter PI(ABS) describe the performance index on absorption basis and is related to the electron transport to PQ pool. In the formula of PI(ABS) are included fluxes of absorption, trapping, dissipation and electron transport to the intersystem electron acceptors.

\subsection{Yield Estimation}

Broccoli heads (16 per experimental plot) were harvested twice ( 4 and 12 September), when flower buds reached a diameter of ca. $2 \mathrm{~mm}$ and were fully formed and compact. Heads were cut together with a fleshy shoot of ca. $15 \mathrm{~cm}$ length. The marketable yield of broccoli, consisting of compact main heads with a minimum diameter of $10 \mathrm{~cm}$, without defects, with closed flower buds, and no symptoms of disease or pest activity, were determined.

\subsection{Statistical Analyses}

All statistical analyses were performed using STATISTICA v. 13.3 (TIBCO Software Inc., Palo Alto, CA, USA). Treatment means were separated by one-way analysis of variance (ANOVA) followed by least significant difference (LSD) with Fischer's test at $p \leq 0.05$. The number of repetitions has been presented 
in the description of the figures. Additionally, cluster analysis and comparison of ranks given to mean values were used. Cluster analysis was performed based on morphological and physiological features (Euclidean distance, Ward's method). The mean values for each parameter were given the rank according to the rule: Rank 1 was given to the worst value for a given parameter, then the mean rank was calculated for each treatment.

\section{Results}

\subsection{Growth Analyses}

As shown in Figure 2a, after 2 and 6 weeks of storage, all broccoli transplants had longer stems compared to the initial value. Long-term storage resulted in greater stem growth, approx $45 \%$ in relation to T0(6). After 2 weeks of storage, plants exposed to the L1 spectrum (T1-2L1) had significantly longer stems than those kept in the dark (T1-2D); and a contrary dependence after 6 weeks was observed. In both storage terms, there were no significant differences in stem length among plants stored in darkness and under L2 spectrum. Control transplants prepared for direct planting (T0), were characterized by a similar height to plants produced after short-term storage. The lowest value of stem diameter (Figure 2b) was observed in broccoli transplants before long-term storage (T0(6)). After 6 weeks, the diameter of stems had increased significantly within all treatments. Shorter storage did not affect the thickness in relation to the initial value with the exception of the L2 light treatment, where an increase was shown. Moreover, after long-term storage, plants exposed to the L2 spectrum had a significantly increased stem diameter compared to L1. There were no significant differences in this growth parameter between control transplants (T0) and each storage group.

The increase of transplant's leaf area was observed both after 2 and 6 weeks of storage (Figure 2c). However, there were no significant differences among groups of plants exposed to various light conditions within a particular storage time. No new leaves appeared during storage (data not shown). The largest leaf blades were observed on plants after 2 weeks of storage, but this increase was not accompanied by an increase in leaf dry matter content (Figure 3a).

\subsection{Chemical Analyses}

Short-term storage caused a decrease in leaf dry matter content (Figure 3a) in comparison to the initial value T0(2) in each group of transplants, in which (wherein) plants kept in the dark exhibited the lowest value. Another relationship was indicated after 6 weeks of storage: The lighting of plants resulted in a significant increase in leaf dry matter, the largest being those under the L2 spectrum (about $30 \%$ compared to $\mathrm{T} 0(6)$ ). It was the highest percentage of leaf dry matter in the experiment.

The content of soluble sugars (Figure $3 \mathrm{~b}$ ) in broccoli leaves significantly decreased in dark conditions but increased with LED lighting of the L1 spectrum at both storage periods. A significant increase in sugars level under L2 light, as a result of long-term storage, was also found. Leaves of control transplants (T0) contained more soluble sugars in relation to all groups of plants, despite L1 and L2 light treatments after 6-week storage. In these two cases, the difference was 0.4 and $0.3 \mathrm{mg}$ per $100 \mathrm{~g}$ of fresh weight, respectively, in relation to T0. For the content of protein in broccoli leaves (Figure 3c), a significant decrease of about $40 \%$ after 2 weeks and $30 \%$ after 6 weeks of storage in darkness was noted. Illuminating the plants, regardless of the spectrum and storage duration, caused an increase in protein content to a level similar to the control transplants produced for direct planting (T0).

As shown in Figure 4a, the highest content of total chlorophyll was detected in broccoli leaves after 6 weeks of storage in the L1 and L2 light treatments. Chlorophylls concentration decreased in dark conditions, regardless of storage time. After 2 weeks under L1 and L2 LED light, chlorophylls content was similar to that obtained before storage (T0(2)); while after 6 weeks, the significant increase under both lights compared to the initial level (T0(6)) was found. The highest content of carotenoid (Figure $4 \mathrm{~b}$ ) was shown in broccoli after 6 weeks of storage in the L1 light treatment; whereas the lowest-in dark and L2 LED light treatments after 2 weeks of storage. The ratio of total chlorophyll 
to carotenoids (Figure 4c) that indicates the greenness of leaves was the highest in broccoli lighted two weeks with L2 spectrum and did not differ significantly from L1 (at this term) as well as from L2 after 6 weeks of storage. The value of this parameter in all three groups was similar to control plants (T0). The content of chlorophyll a, b and the ratio of chlorophyll a/b was presented in Supplementary Materials Figure S1. The relationships for chlorophyll a to $b$ ratio were similar to these demonstrated for the ratio of total chlorophyll to carotenoids.

The content of pheophytin (Figure 5a) was highest in broccoli leaves after 6 weeks of storage in darkness. In this storage term, L2 lighting caused an increase of pheophytin to a level that was not significantly different from the highest one. Two-week storage did not result in significant changes in pheophytin content. A similar level was observed in the transplant leaves before long-term storage, in control plants, and also those illuminated for 6 weeks with L1 light.

Total phenol content in transplant leaves is presented in Figure 5b. Due to technical reasons, no analysis was carried out before transferring plants to storage. According to the available data, after both storage periods, the lighting of plants caused an increase of phenols in relation to the dark treatment. A significant difference was observed between light spectra after 2 weeks of storage; the plants accumulated more phenols in the L1 treatment. Comparing the same light conditions, broccoli leaves had more phenols after long-term storage than short-term. The transplants, which were prepared for direct planting (T0), were characterized by the highest content of these compounds.

Malondialdehyde (MDA) content (Figure 5c) was the lowest in leaves of transplants kept both in darkness (regardless of duration storage) and in the control (T0). After short-term storage, the increase in this compound under the L2 spectrum was found (by about 20\% in relation to T0(2)). Lighting with both spectra, L1 and L2, caused the increase of MDA as an effect of long-term storage (by $40 \%$ and $28 \%$, respectively, compared with T0(6)). Furthermore, 2 weeks with L2 light (T1-2L2) caused more changes associated with MDA accumulation than 6 weeks (T1-6L2).

\subsection{Chlorophyll Fluorescence Analyses}

Some parameters of chlorophyll a fluorescence were presented in Figure 6a-c. No significant difference was observed in Fv/Fm of the leaves in plants before storage (T0(2), T0(6)) and in control (T0) (Figure 6a). There were also no difference in the Fv/Fm between control and lighted leaves. Compared to the initial value, two-week storage in the dark and under the L1 spectrum resulted in a decrease of this parameter. After 6 weeks, the Fv/Fm declined to the lowest level of the experiment under dark conditions. In relation to the values before storage, its decrease under both spectra were also shown. Similar relationships to that of the $\mathrm{Fv} / \mathrm{Fm}$ ratio were demonstrated in the changes of the $\mathrm{Fv} / \mathrm{F}_{0}$ parameter (Figure 6b). However, $\mathrm{Fv}_{\mathrm{v}} / \mathrm{F}_{0}$ significantly decreased in light treatments compared to the control (T0) after 6 weeks of storage. As shown in Figure 6c, PI(ABS) of transplant leaves was highest in the control (T0) and before transferring the plants into long-term storage (T0(6)). Darkness caused a significant decrease in PI(ABS) value by approx 1.7 and 5.5 times after 2 and 6 weeks, respectively, compared with the state before storage. Lighting the plants for 2 weeks, regardless of spectrum, maintained PI(ABS) to a level similar to the initial PI(ABS). However, after 6 weeks, a significant decrease in this parameter was noted. In relation to T0(6), PI(ABS) declined 45 and 28\% under L1 and L2, respectively, though there was no significant difference among the values obtained in both light treatments. 
a

Stem length

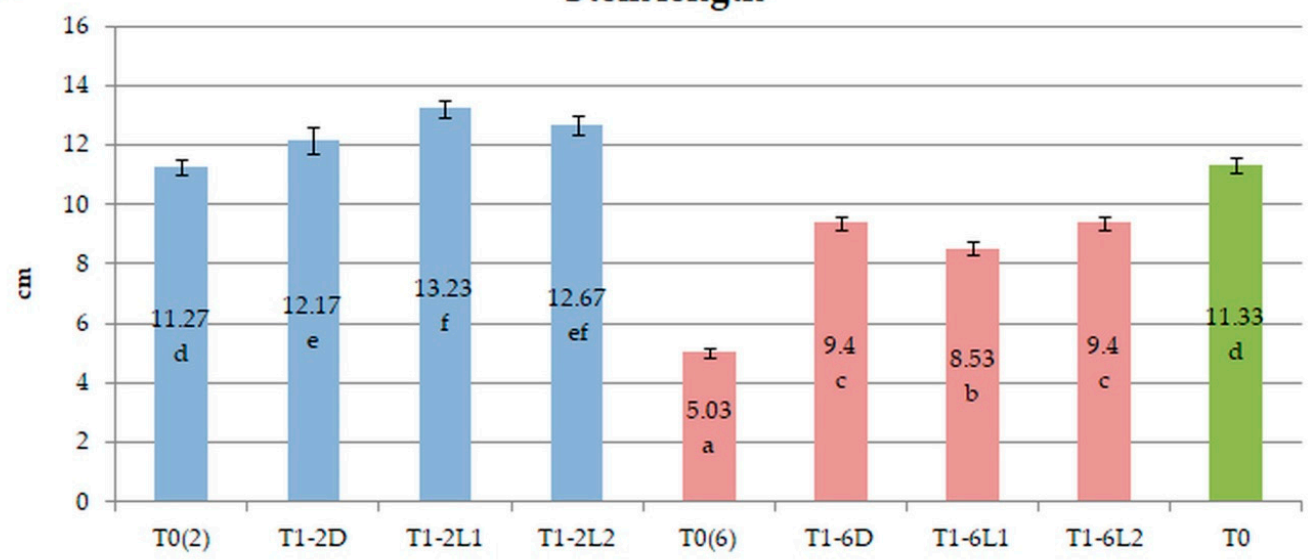

b

Stem diameter

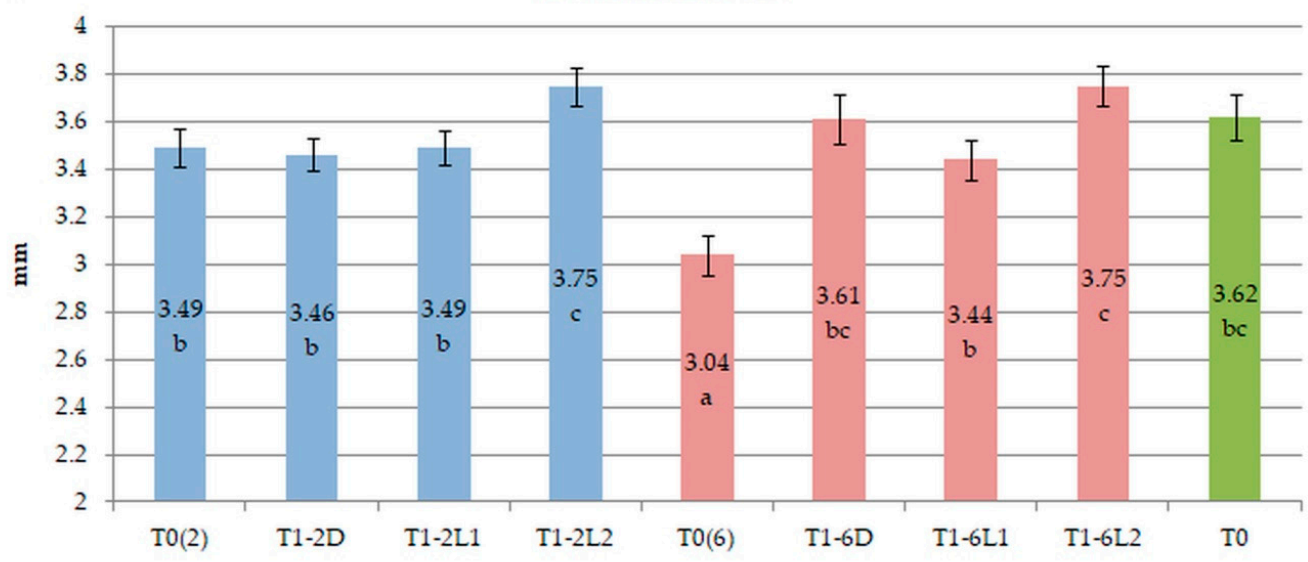

c

\section{Leaf area}

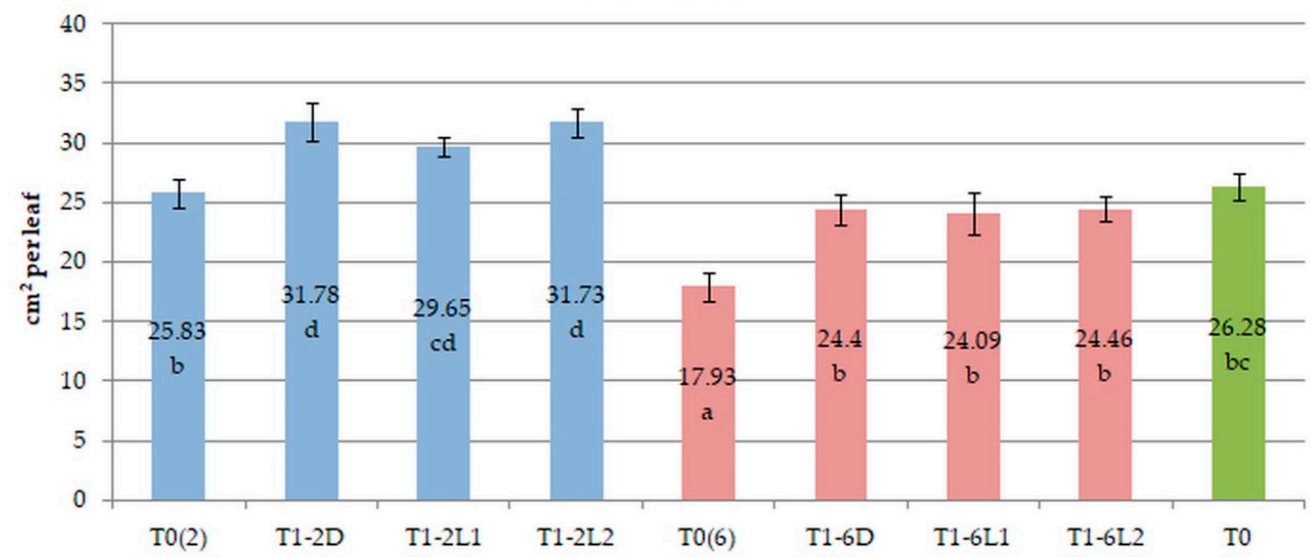

Figure 2. Stem length $(\mathbf{a})$, stem diameter $(\mathbf{b})$, and leaf area $(\mathbf{c})$ of broccoli "Parthenon $\mathrm{F}_{1}$ " transplants in various storage terms and light treatments: T0(2) before 2 weeks of storage (abbreviation. w.s.); T1-2D after 2 w.s. in darkness; T1-2L1 after 2 w.s. in L1 light; T1-2L2 after 2 w.s. in L2 light; T0(6) before 6 w.s.; T1-6D after 6 w.s. in darkness; T1-6L1 after 6 w.s. in L1 light; T1-6L2 after 6 w.s. in L2 light; T0 control plants without storage. Error bars represent the standard error (SE) of biological replicates $(n=20)$. Mean separations were significantly different according to Fisher's least significant difference (LSD) test at $P \leq 0.05$. 
a

Leaf dry matter

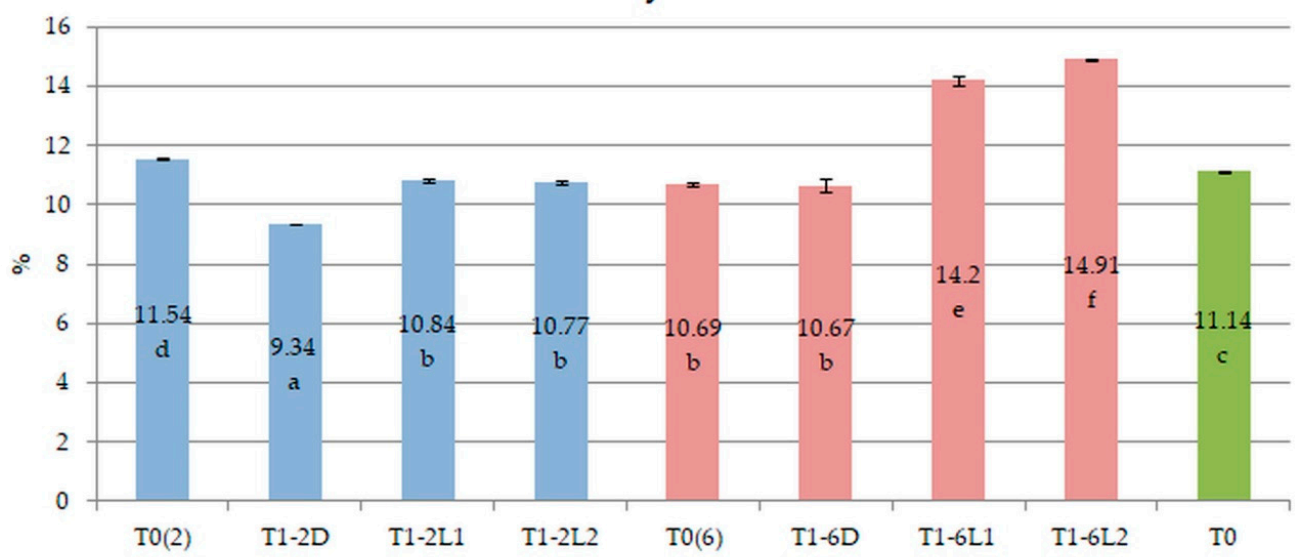

b

Soluble sugars

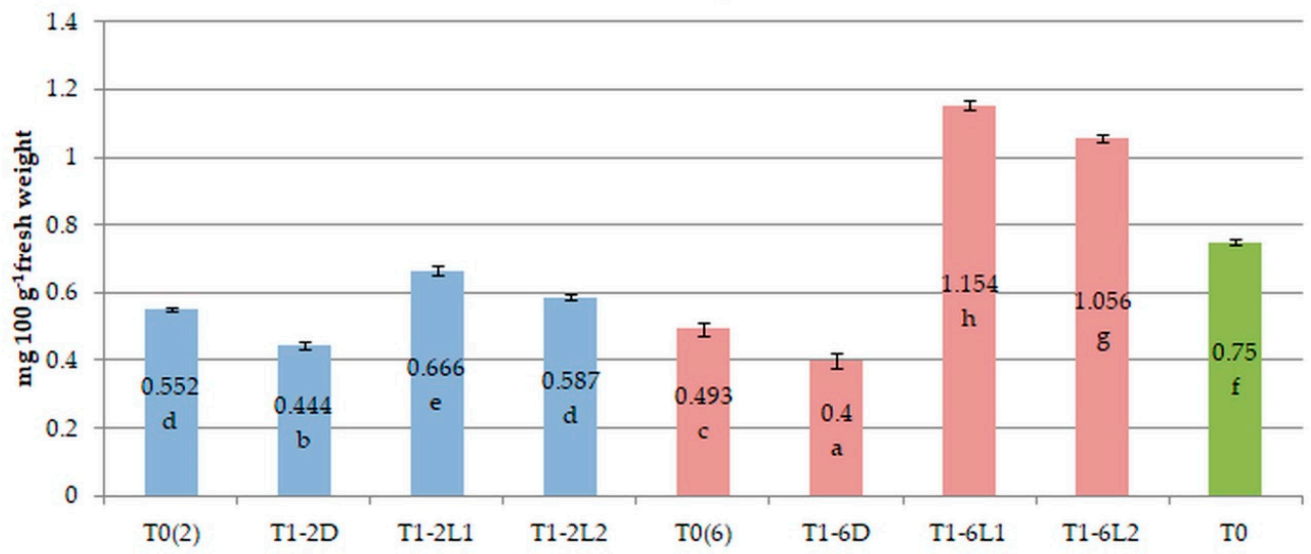

c

\section{Protein}

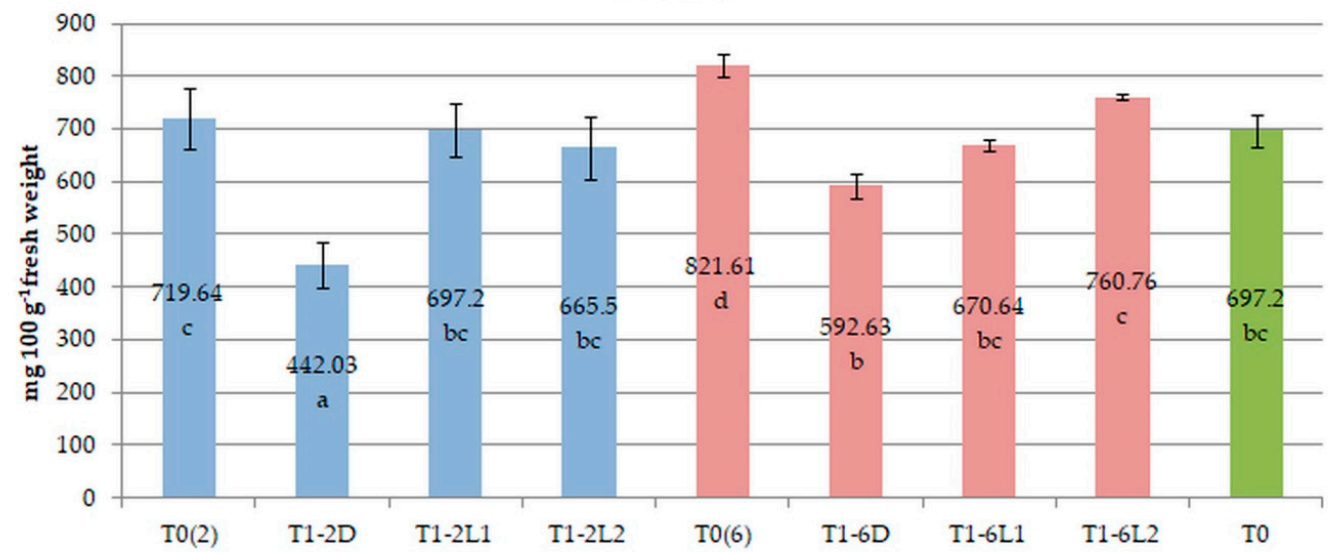

Figure 3. Dry matter (a), soluble sugars $(\mathbf{b})$, and protein $(\mathbf{c})$ content in leaves of broccoli "Parthenon $\mathrm{F}_{1}$ " transplants in various storage terms and light treatments: T0(2) before 2 weeks of storage (abbreviation. w.s.); T1-2D after 2 w.s. in darkness; T1-2L1 after 2 w.s. in L1 light; T1-2L2 after 2 w.s. in L2 light; T0(6) before 6 w.s.; T1-6D after 6 w.s. in darkness; T1-6L1 after 6 w.s. in L1 light; T1-6L2 after 6 w.s. in L2 light; T0 control plants without storage. Error bars represent the standard error (SE) of biological replicates $(n=3)$. Mean separations were significantly different according to Fisher's LSD test at $p \leq 0.05$. 
a

Total chlorophyll

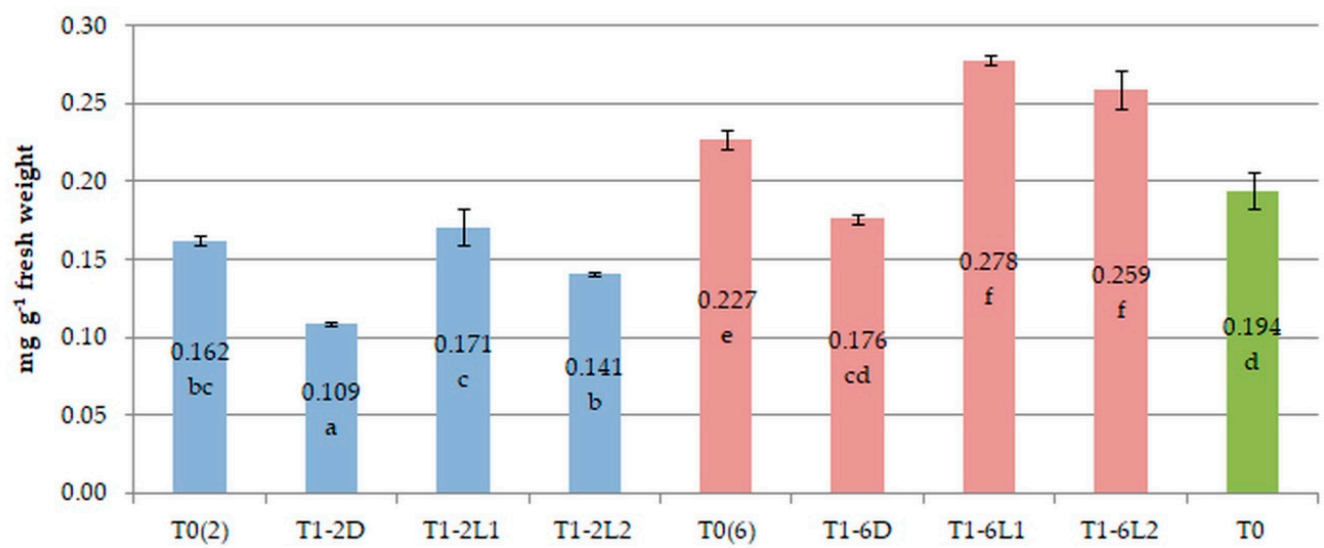

b

Carotenoids

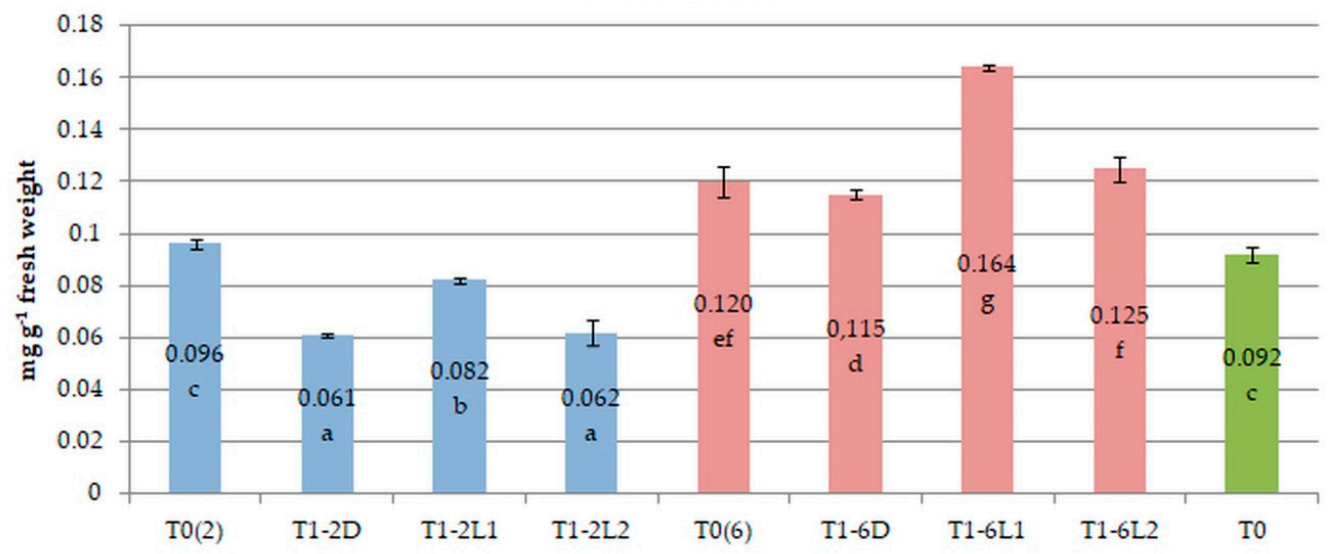

c

Total chlorophyll/carotenoids

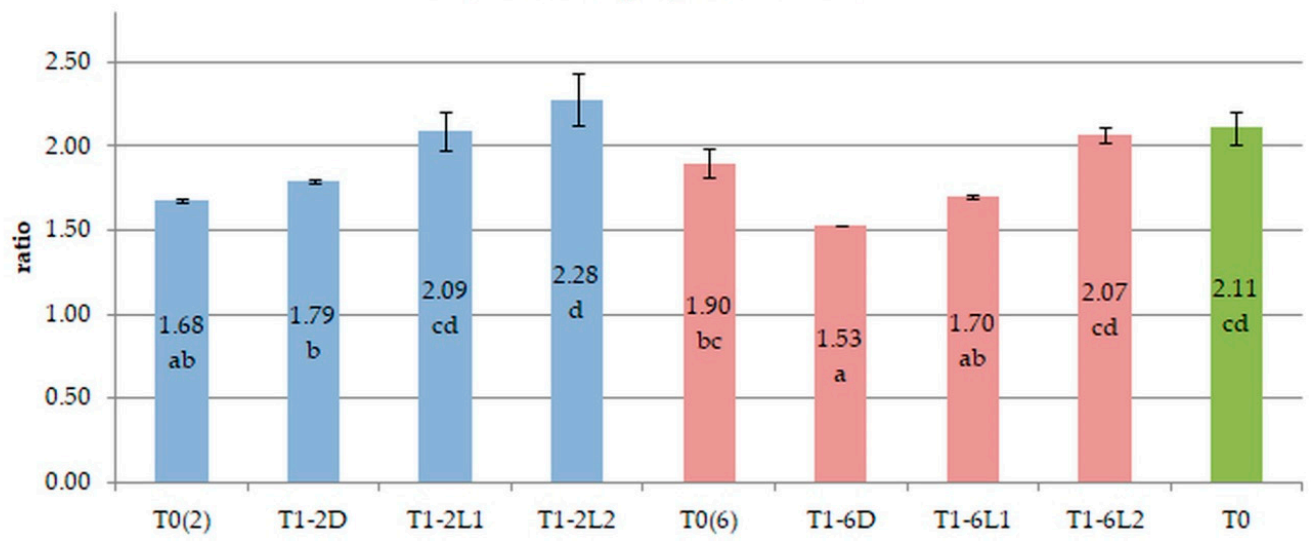

Figure 4. Total chlorophyll (a), carotenoids (b), and total chlorophyll to carotenoids ratio (c) in leaves of broccoli "Parthenon $\mathrm{F}_{1}$ " transplants in various storage terms and light treatments: T0(2) before 2 weeks of storage (abbreviation. w.s.); T1-2D after 2 w.s. in darkness; T1-2L1 after 2 w.s. in L1 light; T1-2L2 after 2 w.s. in L2 light; T0(6) before 6 w.s.; T1-6D after 6 w.s. in darkness; T1-6L1 after 6 w.s. in L1 light; T1-6L2 after 6 w.s. in L2 light; T0 control plants without storage. Error bars represent the standard error (SE) of biological replicates $(n=3)$. Mean separations were significantly different according to Fisher's LSD test at $p \leq 0.05$. 
a

Phaeophytin

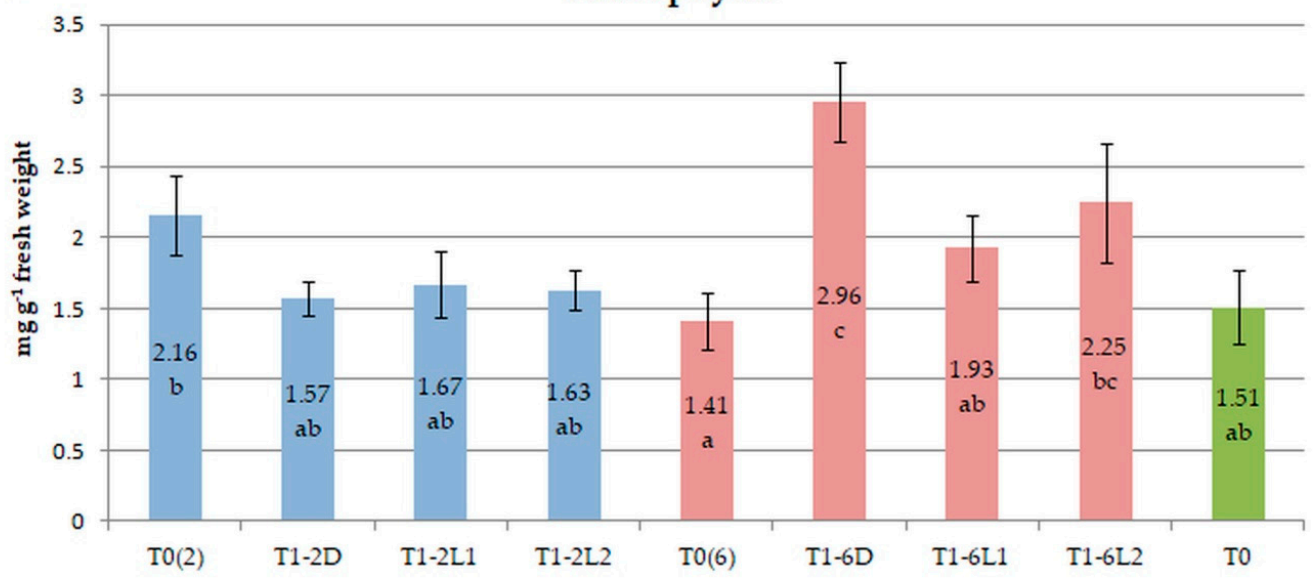

b

Total phenols

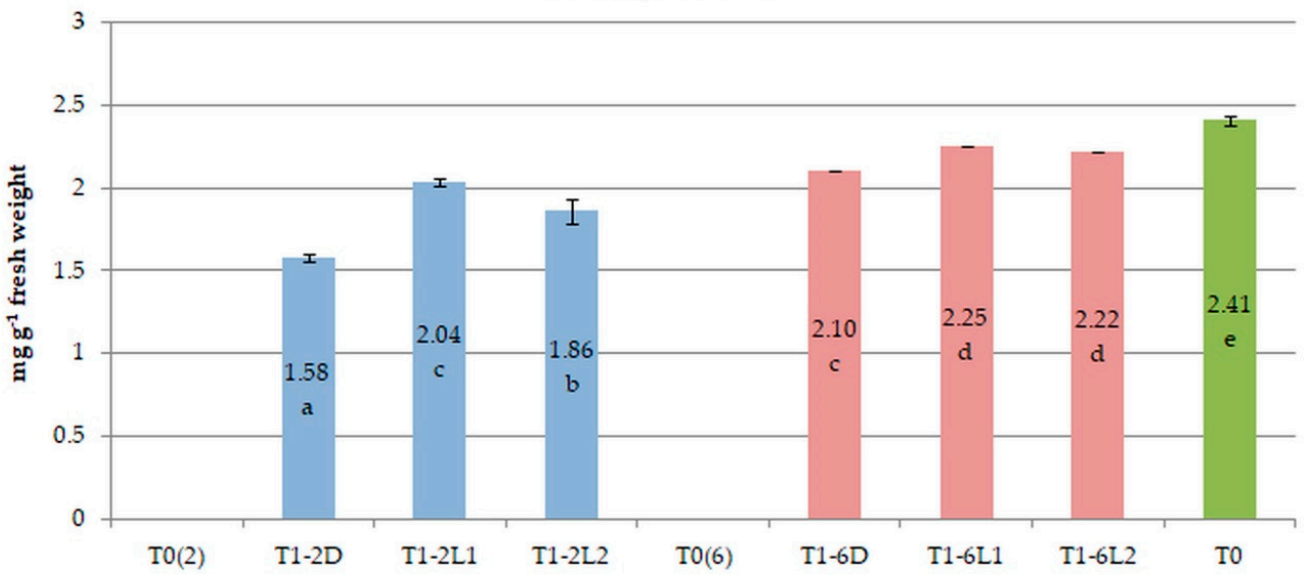

c

MDA

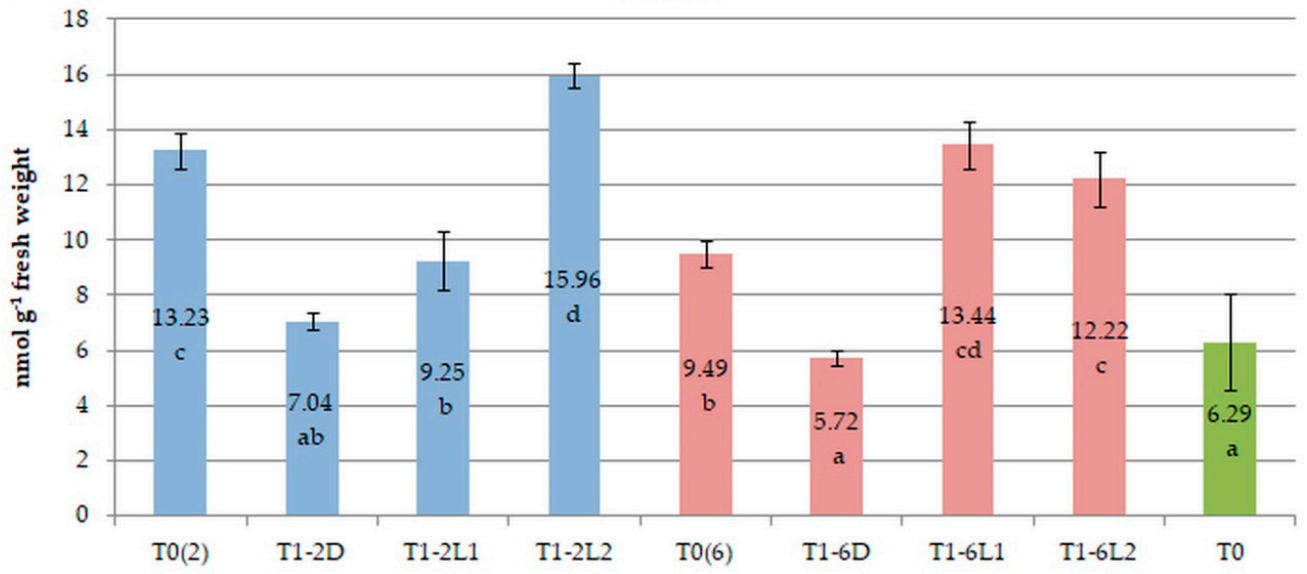

Figure 5. Pheophytine (a), phenols (b), and malondialdehyde (MDA) (c) content in leaves of broccoli "Parthenon $\mathrm{F}_{1}$ " transplants in various storage terms and light treatments: T0(2) before 2 weeks of storage (abbreviation. w.s.); T1-2D after 2 w.s. in darkness; T1-2L1 after 2 w.s. in L1 light; T1-2L2 after 2 w.s. in L2 light; T0(6) before 6 w.s.; T1-6D after 6 w.s. in darkness; T1-6L1 after 6 w.s. in L1 light; T1-6L2 after 6 w.s. in L2 light; T0 control plants without storage. Error bars represent the standard error (SE) of biological replicates $(n=4)$. Mean separations were significantly different according to Fisher's LSD test at $p \leq 0.05$. 
a

Fv/Fm

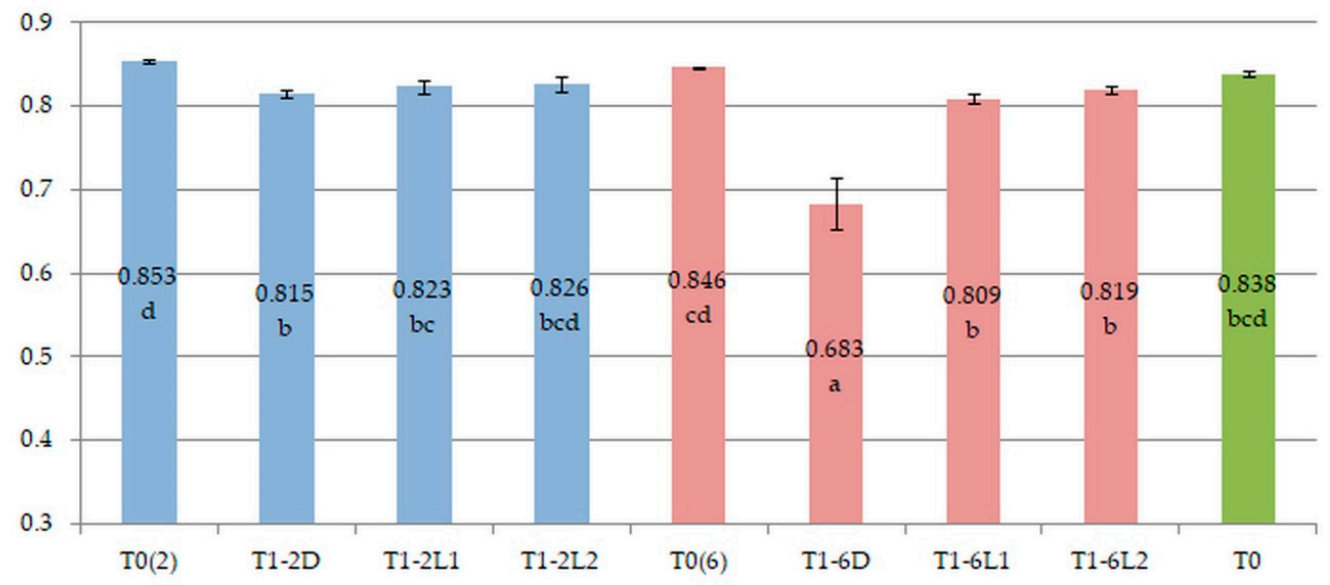

b

$\mathrm{Fv} / \mathrm{F}_{0}$

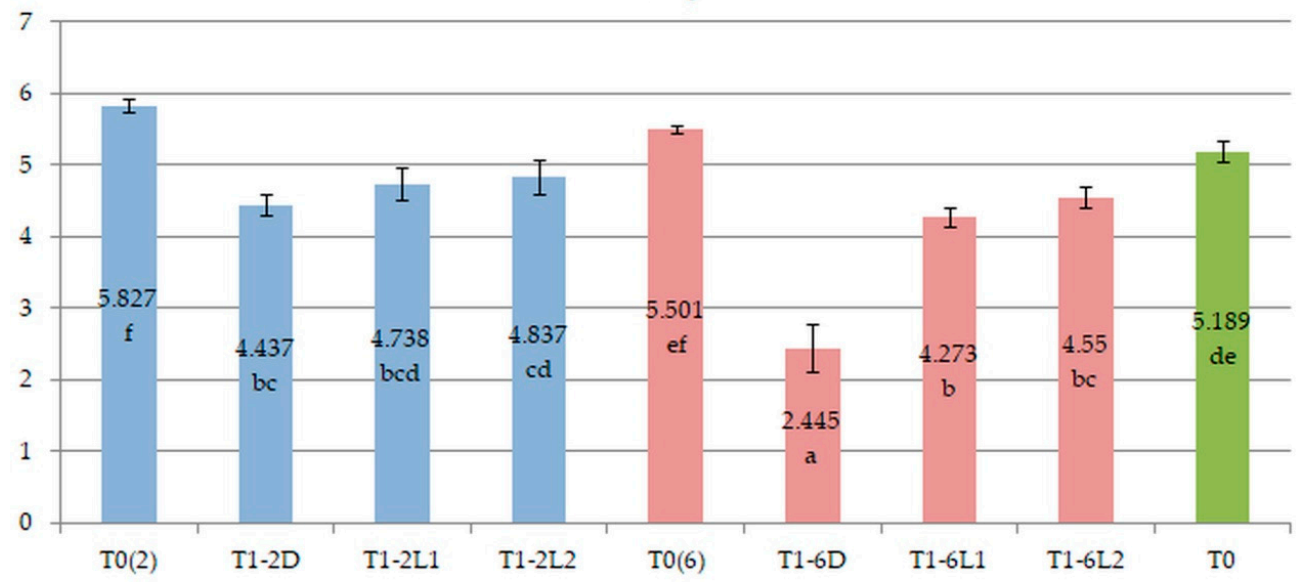

c

PI(ABS)

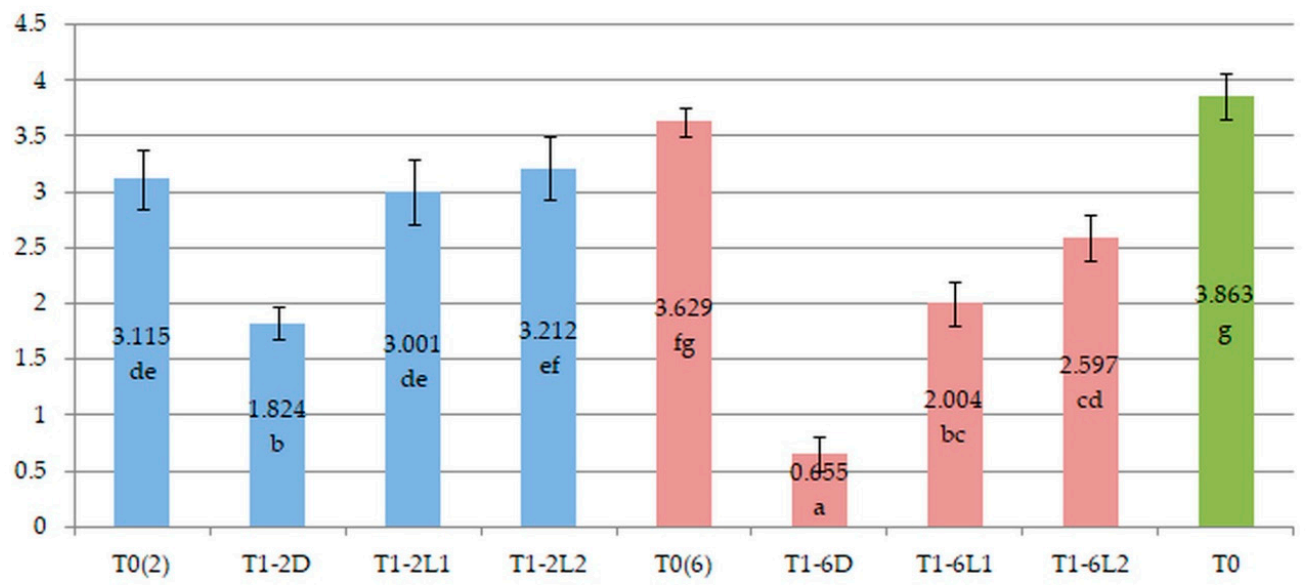

Figure 6. Parameters of chlorophyll a fluorescence: Fv/Fm (a), Fv/F $(\mathbf{b})$ and PI(ABS) (c) of broccoli "Parthenon $\mathrm{F}_{1}$ " leaves in various storage terms and light treatments: T0(2) before 2 weeks of storage (abbreviation. w.s.); T1-2D after 2 w.s. in darkness; T1-2L1 after 2 w.s. in L1 light; T1-2L2 after 2 w.s. in L2 light; T0(6) before 6 w.s.; T1-6D after 6 w.s. in darkness; T1-6L1 after 6 w.s. in L1 light; T1-6L2 after 6w.s. in L2 light; T0 control plants without storage. Error bars represent the standard error (SE) of biological replicates $(n=10)$. Mean separations were significantly different according to Fisher's LSD test at $p \leq 0.05$. 


\subsection{Yield Estimation}

The highest total yield of broccoli heads (Table 3) was recorded in the control group of plants (T0), in which transplants were not stored. Higher yield resulted from higher mass of single broccoli head. Their yield was not significantly different from that of those obtained in plants stored for 2 or 6 weeks under the L2 light spectrum. Additionally, broccoli yielded similarly, but on a significantly lower level than the control. In treatments T1-6L1 and T1-6D broccoli yield was lower by 26 and 23\%, respectively, compared to T0, and in treatments T1-2L1 and T1-2D, it was reduced by $16 \%$.

Table 3. Yield of broccoli "Parthenon $\mathrm{F}_{1}$ " heads by transplant treatment: T1-2D after 2 w.s. (weeks of storage) in darkness; T1-2L1 after 2 w.s. in L1 light; T1-2L2 after 2 w.s. in L2 light; T1-6D after 6 w.s. in darkness; T1-6L1 after 6 w.s. in L1 light; T1-6L2 after 6w.s. in L2 light; T0 control plants without storage. The yield is presented as the mean \pm standard error (SE) of biological replicates $(n=3)$. Mean separations were significantly different according to Fisher's LSD test at $p \leq 0.05$.

\begin{tabular}{cccccccc}
\hline $\begin{array}{c}\text { Transplants } \\
\text { Treatment }\end{array}$ & T1-2D & T1-2L1 & T1-2L2 & T1-6D & T1-6L1 & T1-6L2 & T0 \\
\hline Yield $\left(\mathrm{t} \mathrm{ha}^{-1}\right)$ & $19 \pm 1.2 \mathrm{abc}$ & $19 \pm 0.7 \mathrm{abc}$ & $21 \pm 1.6 \mathrm{~cd}$ & $17 \pm 0.6 \mathrm{ab}$ & $17 \pm 1 \mathrm{a}$ & $20 \pm 0.7 \mathrm{bcd}$ & $23 \pm 0.9 \mathrm{~d}$ \\
\hline
\end{tabular}

To evaluate the aim of the presented study, numerous morphological, physiological, and biochemical analysis were conducted. The experiment included many treatments and for easier analysis of the obtained results and inference, additional statistical analyses were performed (Figure 7). According to results of the cluster analysis, plants stored in darkness for 2 or 6 weeks are in different clusters than not treated or light treated plants (Figure 7a). The longest Euclidean distance to the control was observed in the T1-6D treatment, which indicates the huge loss in quality of these seedlings (Figure 7b). The average value of each parameter in each treatment was changed to rank, where the value 1 was given to the worst value for the given parameter. Mean ranks were then calculated for each treatment. The highest rank was obtained in the case of non-stored seedlings (T0) and the lowest in dark stored plants (Figure 7c). 


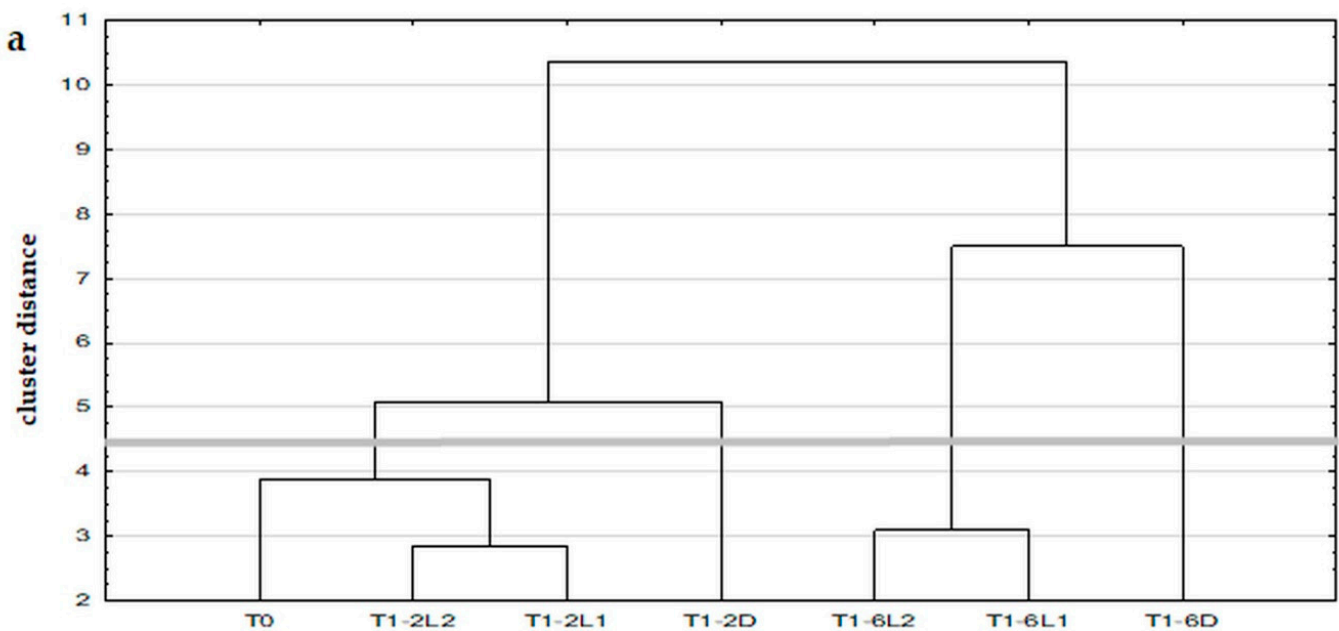

b
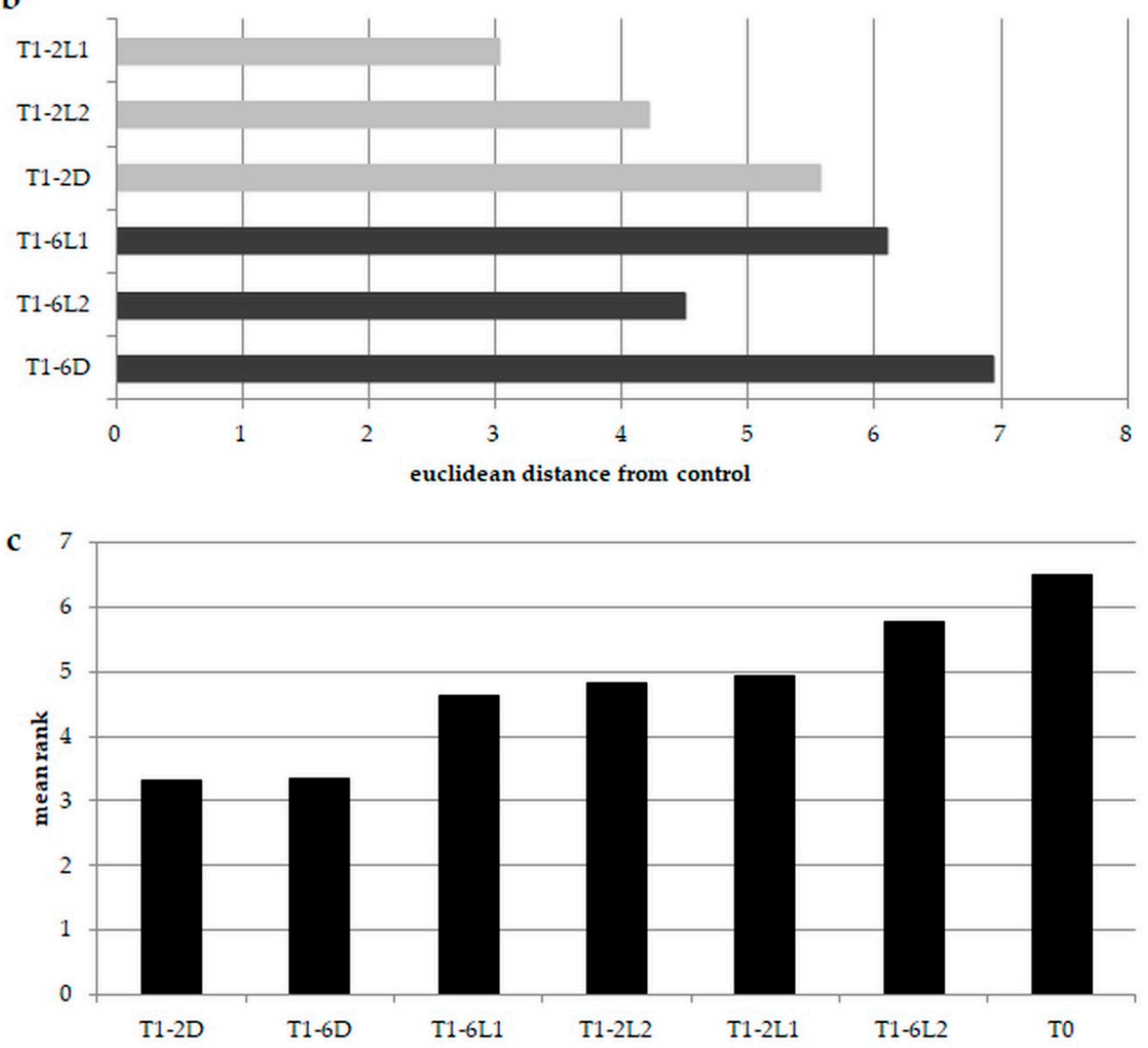

Figure 7. Results of cluster analysis (a) for broccoli plants planted into the field based on morphological and physiological features (Euclidean distance, Ward's method), grey line indicates the cut-off point; Euclidean distance of each treatment planted into the field compared to the control (b), light grey bars indicate 2 weeks of storage treatments, dark grey bars indicate 6 weeks of storage; the value of mean rank (c) of each treatment planted into the field according to all tested parameters; rank 1 was given to the worst value for a given parameter, the higher the rank, the better the parameter. T1-2D after 2 w.s. (weeks of storage) in darkness; T1-2L1 after 2 w.s. in L1 light; T1-2L2 after 2 w.s. in L2 light; T1-6D after 6 w.s. in darkness; T1-6L1 after 6 w.s. in L1 light; T1-6L2 after 6 w.s. in L2 light; T0 control plants without storage. 


\section{Discussion}

The starting point of this experiment was when fully developed 5-weeks-old broccoli transplants were obtained and it was assumed that the term of planting them into the field was delayed by two or six weeks (e.g., during transport or storage). Moreover, all transplants should be planted in a strictly defined period (in this experiment 1 July). Therefore, the main objective of this research was concentrated on the question, which light conditions during short and long-term storage at a cool temperature $\left(4^{\circ} \mathrm{C}\right)$ might allow seedlings to maintain quality parameters. The quality of seedlings transplanted into the field is a crucial element necessary to ensure a high quality and quantity yield. The light treatments used in this study during seedling storage were designed to stop unwanted light-deficiency symptoms, with simultaneous prevention of protein and important secondary metabolite degradation during seedling storage. This would contribute to maintain high crop-forming potential and resistance during broccoli cultivation in the field. Differences shown in stem length and leaf area between plants produced for short- and long-term storage were associated with different greenhouse conditions that occurred during seedlings growth. The insolation and temperature in April-May influenced the slower plant growth compared with May-June (Table 2). In horticultural practice, seedling growers conduct the production mainly in greenhouses, therefore we did not use a growth chamber for that purpose.

Plants have a great ability to acclimate their living processes to dynamically changing environmental conditions. The main aim of plants' adjustment responses is to maintain photosynthesis and growth $[36,37]$. Upon analyzing the growth parameters of broccoli transplants after storage, it was found that stem length and leaf area increased in each treatment, independently of storage duration and light conditions. Transferring young broccoli from a warm greenhouse to a much lower temperature $\left(4{ }^{\circ} \mathrm{C}\right)$ did not stop cell enlargement. Therefore, this result is partially against our hypothesis that a temperature of $4{ }^{\circ} \mathrm{C}$ contributes to stopping growth. The temperature used only slowed down the growth rate. However, no new leaves appeared during storage. Seedlings which were produced for long-term storage had four fully developed true leaves and for short-term storage, five leaves were developed; this number of leaves did not change (data not shown). This suggests that a temperature of $4{ }^{\circ} \mathrm{C}$ could inhibit cell division in the apical meristem but due to water intake, the expansion of stem and leaf cells was not stopped. A greater temperature reduction with the simultaneous use of more blue and UV light in the spectrum during broccoli storage could cause oxidative stress [9,10].

Recently, more and more research has been carried out using UV-A radiation but the effects on morphology and biomass of plants are unequivocal and there is still no comprehensive understanding of the changes that near UV induces [38]. In some studies, UV-A addition stimulated adaxial epidermal thickness, which may further affect the condition of the plants, e.g., lower water evaporation from the leaf surface. In this study, LED light with a 3\% UV-A share in the emitted spectrum effectively increased the stem diameter of broccoli compared to light without UV-A, regardless of storage time. Khoshimkhujaev et al. [39] indicated that UV-A $(376 \mathrm{~nm})$ added to red LEDs significantly improved tomato seedling parameters, including stem diameter that was significantly larger, compared to solely red light. In the 1980s, it was observed that lighting young cabbage plants with UV light inhibited hypocotyl elongation [40], which is a very desirable feature in seedling production (a short and thick stem is preferred). In the presented study, UV-A addition in the spectrum did not inhibit stem elongation, but considering the simultaneous stem diameter stimulation, the overall stocky appearance of a plant was preserved.

Broccoli seedlings illuminated with both kinds of LED light (with more blue or UV-A in spectrum) maintained photosynthesis. This statement is supported by higher soluble sugars and leaf dry matter content compared to storage in the dark. Lie et al. [41] showed that blue LED light $(100 \%$ and $11 \%$ combined with red) promoted soluble sugars accumulation, as well as increased photosynthetic pigment content in Brassica campestris L. In the present study, $42 \%$ blue spectrum (L1) might cause more accumulation of chlorophylls and carotenoids as related to the spectrum with $26 \%$ blue light (L2). However, the influence of the other spectral components cannot be excluded. Many research studies indicate that the chlorophyll content is more affected by the intensity of blue light than its share in 
the spectrum [42]. The stimulating effect of blue light on carotenoid biosynthesis has been shown on various species [43-45]. In recent years, the influence of UV-A on this group of metabolites has been shown [46]. In our study, the use of lighting with a higher share of blue wavelengths (L1) contributed to significantly lower loss (in the case of short-term storage) or even enrichment (long-term storage) of carotenoid concentration in comparison to seedlings stored in the dark. The addition of UV-A radiation (at the expense of blue light share) did not increase carotenoid levels as expected, in comparison to dark storage. A possible explanation is that a sufficiently high blue light intensity is necessary for effective induction of biosynthesis of high carotenoid concentrations [43] and UV-A radiation cannot replace this wavelength band, even though blue and UV-A are characterized by similar wavelength parameters. Another possibility is that carotenoids function as blue light absorbing photosynthetic pigments and chlorophyll photoprotectants. When plants are exposed to lower blue light intensities, the presence of high carotenoid concentration is not necessary to protect chlorophyll molecules from blue light excess and to conduct photosynthesis effectively.

Compared to dark storage, a low intensity of LED light may delay senescence of perishable leafy vegetables [24]. The lighting of broccoli seedlings maintained the protein content to a similar level as that of control plants, regardless of storage duration. In the dark, leaf senescence occurred faster, which was reflected in protein degradation. Additionally, after six weeks of storage, a significant increase of pheophytin, the product of chlorophyll degradation, occurred. Nevertheless, the use of LED lighting during long-term storage helped to reduce chlorophyll loss and pheophytin formation, which, together with reduced protein degradation, may suggest a successful attempt to slow down senescence-associated processes in stored broccoli seedlings.

The relative energy of solar radiation is high in the UV-blue wavelength regions [47], and the glass covers used in most greenhouses in which vegetable seedlings are produced are mostly impenetrable by UV radiation. A rapid change in conditions after transplanting plants into the uncovered field, without protection against this high energy radiation, can be a potential source of light stress. This may cause further consequences, resulting in the weakening of plant growth and overall condition. We assumed that low irradiation with a specific light spectrum during broccoli seedlings storage would be beneficial for decreasing light stress, which may occur after planting them into the natural environment. Phenolic compounds are known to be involved in alleviating light stress, acting as UV-screens and antioxidants [48] and play an important role in light environment adaptation [49]. Their synthesis in larger quantities, as a result of UV and violet-blue radiation was observed previously [50]. In the present study, broccoli transplant irradiation increased the total phenolic compounds in comparison to storage under dark conditions. According to previously cited works [48-50], a higher content of phenols in examined plants might result in better acclimation to changed light conditions during planting outside the covered greenhouse. The argument suggesting veracity of this hypothesis might be the higher yield of broccoli obtained from seedlings illuminated during storage by a light spectrum enriched with UV-A, especially after 6 weeks of storage.

MDA is an indicator of lipid peroxidation, which might be caused by uncontrolled accumulation of reactive oxygen species (ROS) [51]. ROS are produced in many plant cell compartments during metabolism or its disturbance. We observed that the metabolism of plants kept in darkness was slowed (lower rate of: Photosynthesis and sugars, protein, and pigment content). It is likely that the production of ROS was also lower and according to a previous study [52], the activity of antioxidant enzymes in darkness is quite high. That might be the reason for a reduced amount of MDA in plants kept in the dark. Previous experiments indicated that keeping broccoli transplants in a dark cold room $\left(2{ }^{\circ} \mathrm{C}\right)$ may positively affect the activity of an important antioxidant enzyme, catalase. Moreover, this sort of treatment contributed to increased soluble peroxidase activity in a long-term manner, namely at the time of harvest [52]. The presented work did not consider parameters regarding the activity of antioxidant enzymes, but their possible increased activity could have caused a noticeable decrease in MDA values compared to the initial values in the case of seedlings stored in the dark. 
During greenhouse cultivation of transplants, external conditions, like high temperature, low relative humidity, and high solar radiation, may have induced lipid peroxidation and accumulation of MDA. Plants prepared for 2 weeks of storage were cultivated at a higher temperature and solar radiation than those prepared for 6 weeks of storage (Table 2), therefore, T0(2) plants had higher MDA content than T0(6). Production of 5-week-old seedlings was performed in the greenhouse, under a glass cover, which does not transmit UV-A radiation originating from sunlight. The addition of $3 \%$ UV-A to the spectrum received by plants just after moving them to the storage room might be stress-generating during the initial period. This was visible after two weeks of storage, when the degree of membrane damage measured by MDA content was highest and exceeded almost two-fold the level of MDA shown in plants illuminated without UV in the spectrum. Plants stored for six weeks with or without an UV-A enriched illumination spectrum had a similar level of MDA, which was higher than plants stored in darkness or those that were not stored. Notably, some lipid peroxidation products, like MDA, may also have signaling functions in response to stress and change the expression of some genes $[53,54]$. The adaptation of plants was demonstrated by a high yield of broccoli collected from plants that were illuminated with UV-A spectrum during storage. The crop level was similar to that obtained from broccoli planted in the field immediately after seedlings were produced.

The presented records indicate that the best yield was obtained from broccoli transplants planted to the field directly after finishing their production. However, in certain circumstances, when direct seedling planting is not possible during the scheduled time, keeping broccoli transplants in cool conditions with a low intensity light enriched with $3 \%$ UV-A radiation may result in obtaining a satisfying yield quantity, comparable to those crops grown from non-stored seedlings. Storage of broccoli transplants at $4{ }^{\circ} \mathrm{C}$ in the dark for 2 or 6 weeks led to significantly lower yield in comparison to non-stored plants. It demonstrates the need to modify seedling storage conditions to prevent financial losses for broccoli producers. Our results show that the introduction of proper lighting into storage chambers for broccoli seedlings can be a good way to prevent losses resulting from the delay in planting seedlings to the field.

Disturbances in photosynthesis can be observed during cold stress, light deficiency, oxidative stress or other stress factors [55] due to reduction in photosynthetic pigment content, inhibition in enzyme activity, stomatal closure, disorders in the electron transport chain, or light absorption. One of the methods used for the evaluation of photosynthetic apparatus efficiency is the chlorophyll a fluorescence measurement [56]. Both parameters $\mathrm{Fv} / \mathrm{Fm}$ and $\mathrm{Fv} / \mathrm{F}_{0}$ are considered universal tools to indicate various stress factors in plants [57]. During stress conditions, a decrease in the Fv/Fm ratio can be observed [58]. However, the maximum quantum yield of PS II ( $\mathrm{Fv} / \mathrm{Fm})$ revealed no stress state in illuminated broccoli after short and long-term storage, being on the same level as that of the control T0 plants. What is interesting is that only long-term storage in the dark decreased the Fv/Fm parameter below 0.8 . The $\mathrm{Fv} / \mathrm{F}_{0}$ parameter, considered a more sensitive stress indicator, substantially decreased after transferring the plants to storage (Figure 6) but again the lowest value was obtained in the case of plants after 6 weeks of storage in darkness. The most sensitive indicator of changes in the state of the photosynthetic apparatus in the presented experiment seems to be the PI(ABS) index, in which the changes were greatest. These observations are similar to Kalaji et al. [59] who observed that PI(ABS) was the parameter most sensitive to different conditions. The examined chlorophyll a fluorescence parameter indicated that the photosynthetic apparatus of plants stored for the longest time in the dark were subjected to the greatest stress. Using LED lights during storage improves the function of the photosynthetic apparatus, especially in the case of long-term treatment.

The main purpose of the study was to compare seedlings ready for planting (stored or not), therefore, only treatments that were planted to the field were used in cluster analysis (Figure 7). These results clearly indicate that in the experiment, light conditions improved the quality of seedlings and increased the obtained yield. Notably, long-term storage and light with the addition of UV-A radiation improved seedling quality and subsequently plant yield. 


\section{Conclusions}

In conclusion, the presented results are in line with the first hypothesis, according to which the use of proper LED lighting (particularly the spectrum containing 3\% UV-A radiation) during broccoli seedling storage may help with obtaining satisfying yield, comparable to those from plants not subjected to storage. However, applied storage conditions did not contribute to full inhibition of plant growth, as we hypothesized. In general, providing two LED spectral compositions during cold storage resulted in maintaining favorable morphological, photosynthetic, and biochemical parameters of broccoli transplants in comparison to dark stored plants, which agrees with our second hypothesis. The presented research showed great potential to use LED lighting in broadly understood horticulture, not only during cultivation of plants under covers or storage of harvested crops, as it was proved before in numerous experiments, but also to prevent losses in the event of the necessity of long-term transport of seedlings or random incidents forcing the delay of planting. Promising effects were obtained, especially by adding UV-A radiation to the lighting spectrum.

Supplementary Materials: The following are available online at http://www.mdpi.com/2073-4395/10/7/1009/s1, Figure S1: Chlorophyll a (a), chlorophyll b (b), and chlorophyll a to b ratio (c) in leaves of broccoli "Parthenon $\mathrm{F}_{1}$ " transplants in various storage terms and light treatments: T0(2) before 2 weeks of storage (abbr. w.s.); T1-2D after 2 w.s. in darkness; T1-2L1 after 2 w.s. in L1 light; T1-2L2 after 2 w.s. in L2 light; T0(6) before 6 w.s.; T1-6D after 6 w.s. in darkness; T1-6L1 after 6 w.s. in L1 light; T1-6L2 after 6 w.s. in L2 light; T0 control plants without storage. Error bars represent the standard error (SE) of biological replicates $(n=3)$. Mean separations were significantly different according to Fisher's LSD test at $p \leq 0.05$.

Author Contributions: Conceptualization, R.W. and E.K.; methodology, R.W., A.K., O.D.-G.; formal analysis, R.W., A.K.; investigation, E.K.; data curation, R.W., A.K.; writing-original draft preparation, R.W., E.K., A.K., O.D.-G.; writing-review and editing, R.W., E.K., A.K., O.D.-G.; visualization, A.K. All authors have read and agreed to the published version of the manuscript.

Funding: This research was financed by the Ministry of Science and Higher Education of the Republic of Poland (SUB/2020-050012-D011, SUB/2020-050013-D011).

Acknowledgments: We would like to thank Paweł Pyzik (plant care) and Monika Komorowska (laboratory work) for technical support.

Conflicts of Interest: The authors declare no conflict of interest.

\section{References}

1. Klepacki, B.; Perkowska, A. Organization of food supply chains in dispersed production on the example of the vegetable sector in Poland. Ann. PAAAE 2020, 22, 149-158. [CrossRef]

2. Sánchez-Pujante, P.J.; Gionfriddo, M.; Sabater-Jara, A.B.; Almagro, L.; Pedreño, M.A.; Diaz-Vivancos, P. Enhanced bioactive compound production in broccoli cells due to coronatine and methyl jasmonate is linked to antioxidative metabolism. J. Plant Physiol. 2020, 248, 153136. [CrossRef] [PubMed]

3. Peñas, E.; Zielińska, D.; Gulewicz, P.; Zieliński, H.; Frias, J. Vitamin C, phenolic compounds and antioxidant capacity of broccoli florets grown under different nitrogen treatments combined with selenium. Pol. J. Food Nutr. Sci. 2018, 68, 179-186. [CrossRef]

4. Conversa, G.; Lazzizera, C.; Bonasia, A.; Elia, A. Harvest season and genotype affect head quality and shelf-life of ready-to-use broccoli. Agronomy 2020, 10, 527. [CrossRef]

5. Borowski, J.; Szajdek, A.; Borowska, E.J.; Ciska, E.; Zieliński, H. Content of selected bioactive components and antioxidant properties of broccoli (Brassica oleracea var. italica L.). Eur. Food Res. Technol. 2007, 226, 459-465. [CrossRef]

6. Abbaoui, B.; Riedl, K.M.; Ralston, R.A.; Thomas-Ahner, J.M.; Schwartz, S.J.; Clinton, S.K.; Mortazavi, A. Inhibition of bladder cancer by broccoli isothiocyanates sulforaphane and erucin: Characterization, metabolism, and interconversion. Mol. Nutr. Food Res. 2012, 56, 1675-1687. [CrossRef]

7. Hwang, J.-H.; Lim, S.-B. Antioxidant and anticancer activities of broccoli by-products from different cultivars and maturity stages at harvest. Prev. Nutr. Food Sci. 2015, 20, 8-14. [CrossRef]

8. Kaczperski, M.P.; Armitage, A.M. Short-term storage of plug-grown bedding plant seedlings. HortScience 1992, 27, 798-800. [CrossRef] 
9. Grabowska, A.; Kunicki, E.; Kalisz, A.; Wojciechowska, R.; Leja, M.; Sękara, A. Chilling stress applied to broccoli transplants of different age affects yield of the plants cultivated in summer. Hortic. Sci. (Prague) 2014, 41, 71-79. [CrossRef]

10. Kalisz, A.; Sekara, A.; Grabowska, A.; Cebula, S.; Kunicki, E. The effect of chilling stress at transplant stage on broccoli development and yield with elements of modeling. J. Plant Growth Regul. 2015, 34, 532-544. [CrossRef]

11. Kubota, C. Environmental control for growth suppression and quality preservation of transplants. Environ. Control Biol. 2003, 41, 97-105. [CrossRef]

12. Yamashita, I.; Dan, K.; Shimomura, M. Active modified atmosphere packaging storage of cabbage plug seedlings. J. Japan Soc. Hort. Sci. 1999, 68, 1015-1021. [CrossRef]

13. Sato, F.; Yoshioka, H.; Fujiwara, T.; Higashio, H.; Uragami, A.; Tokuda, S. Physiological responses of cabbage plug seedlings to water stress during low-temperature storage in darkness. Sci. Hortic. 2004, 101, 349-357. [CrossRef]

14. Grabowska, A.; Sękara, A.; Bieniasz, M.; Kunicki, E.; Kalisz, A. Dark-chilling of seedlings affects initiation and morphology of broccoli inflorescence. Not. Bot. Horti Agrobot. Cluj. Napoca. 2013, 41, 213-218. [CrossRef]

15. Wilson, S.B.; Iwabuchi, K.; Rajapakse, N.C.; Young, R.E. Responses of broccoli seedlings to light quality during low-temperature storage in vitro: I. Morphology and survival. HortScience 1998, 33, $1253-1257$. [CrossRef]

16. Sato, F.; Okada, K. Daily red LED illumination improves the quality of cabbage plug seedlings during low-temperature storage. J. Hortic. Sci. Biotechnol. 2014, 89, 179-184. [CrossRef]

17. Viršilè, A.; Olle, M.; Duchovskis, P. LED lighting in horticulture. In Light Emitting Diodes for Agriculture; Dutta Gupta, S., Ed.; Springer: Berlin, Germany, 2017; pp. 113-147.

18. Wojciechowska, R.; Kołton, A.; Długosz-Grochowska, O.; Kunicki, E.; Mrowiec, K.; Bathelt, P. LED lighting affected the growth and metabolism of eggplant and tomato transplants in greenhouse. Hort. Sci. 2020, in press.

19. Pardo, G.P.; Aguilar, C.H.; Martinez, F.R.; Pacheco, A.D.; González, C.M.; Canseco, M. Effects of light emitting diode high intensity on growth of lettuce (Lactuca sativa L.) and broccoli (Brassica oleracea L.) seedlings. Annu. Res. Rev. Biol. 2014, 4, 2983-2994. [CrossRef]

20. Bantis, F.; Smirnakou, S.; Ouzounis, T.; Koukounaras, A.; Ntagkas, N.; Radoglou, K. Current status and recent achievements in the field of horticulture with the use of light-emitting diodes (LEDs). Sci. Hortic. 2018, 235, 437-451. [CrossRef]

21. Xiaoying, L.; Shirong, G.; Taotao, C.; Zhigang, X.; Tezuka, T. Regulation of the growth and photosynthesis of cherry tomato seedlings by different light irradiations of light emitting diodes (LED). Afr. J. Biotechnol. 2012, 11, 6169-6177. [CrossRef]

22. Kang, W.H.; Park, J.S.; Park, K.S.; Son, J.E. Leaf photosynthetic rate, growth, and morphology of lettuce under different fractions of red, blue, and green light from light-emitting diodes (LEDs). Hortic. Environ. Biotechnol. 2016, 57, 573-579. [CrossRef]

23. Samuolienè, G.; Brazaitytè, A.; Duchovskis, P.; Viršilè, A.; Jankauskienè, J.; Sirtautas, R.; Novickovas, A.; Skalauskienè, S.; Sakalauskaite, J. Cultivation of vegetable transplants using solid-state lamps for the short-wavelength supplementary lighting in greenhouses. Acta Hortic. 2012, 952, 885-892. [CrossRef]

24. D'Souza, C.; Yuk, H.-G.; Khoo, G.H.; Zhou, W. Light-emitting diodes in postharvest quality preservation and microbiological food safety. In Light Emitting Diodes for Agriculture; Dutta Gupta, S., Ed.; Springer: Berlin, Germany, 2017; pp. 191-235.

25. Hasperué, J.H.; Guarddianelli, L.; Rodoni, L.M.; Chavesa, A.R.; Martinezc, G.A. Continuous white-blue LED light exposition delays postharvest senescence of broccoli. LWT Food Sci. Technol. 2016, 65, 495-502.

26. Braidot, E.; Petrussa, E.; Perreson, C.; Patuia, S.; Bertolinia, A.; Tubarob, F.; Wählbyc, U.; Coanc, M.; Vianelloa, A.; Zancania, M. Low-intesity light cycles improve the quality of lamb's lettuce (Varianella olitoria [L.] Pollich) during storage at low temperature. Postharvest Biol. Technol. 2014, 90, 15-23. [CrossRef]

27. Neugart, S.; Schreiner, M. UVB and UVA as eustressors in horticultural and agricultural crops. Sci. Hortic. 2018, 234, 370-381. [CrossRef]

28. Štroch, M.; Materová, Z.; Vrábl, D.; Karlický, V.; Šigut, L.; Nezval, J.; Špunda, V. Protective effect of UV-A radiation during acclimation of the photosynthetic apparatus to UV-B treatment. Plant Physiol. Biochem. 2015, 96, 90-96. [CrossRef] 
29. Yemm, E.W.; Wills, A.J. The estimation of carbohydrates in plant extracts by anthrone. Biochem. J. 1954, 57, 508-514. [CrossRef]

30. Bradford, M.M. A rapid and sensitive method for the quantitation of microgram quantities of protein utilizing the principle of protein-dye binding. Anal. Biochem. 1976, 72, 248-254. [CrossRef]

31. Lichtenthaler, H.K.; Wellburn, A.R. Determinations of a total carotenoids and chlorophylls a and b of leaf extracts in different solvents. Biochem. Soc. Trans. 1983, 603, 591-592. [CrossRef]

32. Axler, R.C.; Owen, C.J. Measuring chlorophyll and phaeophytin: Whom should you believe? Lake Reservoir Manag. 1994, 8, 143-151. [CrossRef]

33. Cicco, N.; Lanorte, M.T.; Paraggio, M.; Viggiano, M.; Lattanzio, V. A reproducible, rapid and inexpensive Folin-Ciocalteau micro-method in determining phenolics of plant methanol extracts. Microchem. J. 2009, 91, 107-110. [CrossRef]

34. Du, Z.; Bramlage, W.J. Modified thiobarbituric acid assay for measuring lipid oxidation in sugar-rich plant tissue extracts. J. Agric. Food Chem. 1992, 40, 1566-1570. [CrossRef]

35. Stirbet, A.; Lazár, D.; Kromdijk, J.; Govindjee. Chlorophyll a fluorescence induction: Can just a one-second measurement be used to quantify abiotic stress responses? Photosynthetica 2018, 56, 86-104. [CrossRef]

36. Ruban, A. Evolution under sun: Optimizing light harvesting in photosynthesis. J. Exp. Bot. 2015, 66, 7-23. [CrossRef] [PubMed]

37. Pockock, T. Influence of light-emitting diodes (LEDs) on light sensing and signaling networks in plants. In Light Emitting Diodes for Agriculture; Dutta Gupta, S., Ed.; Springer: Berlin, Germany, 2017; pp. 37-58.

38. Verdaguer, D.; Jansen, M.A.K.; Llorens, L.; Morales, L.O.; Neugart, S. UV-A radiation effects on higher plants: Exploring the known unknown. Plant Sci. 2017, 255, 72-81. [CrossRef] [PubMed]

39. Khoshimkhujaev, B.; Kwon, J.K.; Park, K.S.; Choi, H.G.; Lee, S.Y. Effect of monochromatic UV-A LED irradiation on the growth of tomato seedlings. Hortic. Environ. Biotechnol. 2014, 55, 287-292. [CrossRef]

40. Lercari, B.; Sodi, F.; Sbrana, C. Comparison of photomorphogenic responses to UV light in red and white cabbage (Brassica oleracea L.). Plant Physiol. 1989, 90, 345-350. [CrossRef]

41. Li, H.; Tang, C.; Xu, Z.; Liu, X.; Han, X. Effects of different sources on the growth of non-heading Chinese cabbage (Brassica campestris L.). J. Agric. Sci. 2012, 4, 262-269. [CrossRef]

42. Kopsel, D.A.; Sams, C.E.; Morrow, R.C. Blue wavelengths from LED lighting increase nutritionally important metabolites in specialty crops. HortScience 2015, 50, 1285-1288. [CrossRef]

43. Samuoliene, G.; Virsile, A.; Brazaityte, A.; Jankauskiene, J.; Sakalauskiene, S.; Vastakaite, V.; Novickovas, A.; Viskeliene, A.; Sasnauskas, A.; Duchovskis, P. Blue light dosage affects carotenoids and tocopherols in microgreens. Food Chem. 2017, 228, 50-56. [CrossRef]

44. Hoffmann, A.M.; Noga, G.; Hunsche, M. Alternating high and low intensity of blue light affects PSII photochemistry and raises the contents of carotenoids and anthocyanins in pepper leaves. Plant Growth Regul. 2016, 79, 275-285. [CrossRef]

45. Mohanty, B.; Lakshmanan, M.; Lim, S.-H.; Kim, J.K.; Ha, S.-H.; Lee, D.-Y. Light-specific transcriptional regulation of the accumulation of carotenoids and phenolic compounds in rice leaves. Plant Signal. Behav. 2016, 11, e1184808. [CrossRef] [PubMed]

46. Brazaityte, A.; Viršile, A.; Samuoliene, G.; Vaštakaite-Kairiene, V.; Jankauskiene, J.; Miliauskiene, J.; Novickovas, A.; Duchovskis, P. Response of mustard microgreens to different wavelengths and durations of UV-A LEDs. Front. Plant Sci. 2019, 10, 1153. [CrossRef]

47. Dutta Gupta, S.; Agarwal, A. Artificial lighting system for plant growth and development: Chronological advancement, working principles and comparative assessment. In Light Emitting Diodes for Agric; Dutta Gupta, S., Ed.; Springer: Berlin, Germany, 2017; pp. 1-26.

48. Bieza, K.; Lois, R. An Arabidopsis mutant tolerant to lethal ultraviolet-B levels shows constitutively elevated accumulation of flavonoids and other phenolics. Plant Physiol. 2001, 126, 1105-1115. [CrossRef]

49. Kliebenstein, D.J. Secondary metabolites and plant/environment interactions: A view through Arabidopsis thaliana tinged glasses. Plant Cell Environ. 2004, 27, 675-684. [CrossRef]

50. Taulavouri, K.; Pyysalo, A.; Taulavouri, T.; Julkunen-Titto, R. Responses of phenolic acid and flavonoid synthesis to blue and blue-violet light depends on plant species. Environ. Exp. Bot. 2018, 150, 183-187. [CrossRef]

51. Czarnocka, W.; Karpiński, S. Friend or foe? Reactive oxygen species production, scavenging and signaling in plant response to environmental stresses. Free Radic. Biol. Med. 2018, 122, 4-20. [CrossRef] [PubMed] 
52. Długosz-Grochowska, O.; Leja, M.; Grabowska, A.; Kunicki, E. The effect of preliminary chilling of broccoli transplants on some antioxidative parameters. Folia Hort. 2012, 24, 131-139.

53. Farmer, E.E.; Mueller, M.J. ROS-mediated lipid peroxidation and RES-activated signaling. Annu. Rev. Plant Biol. 2013, 64, 429-450. [CrossRef] [PubMed]

54. Yalcinkaya, T.; Uzilday, B.; Ozgur, R.; Turkan, I.; Mano, J.I. Lipid peroxidation-derived reactive carbonyl species (RCS): Their interaction with ROS and cellular redox during environmental stresses. Environ. Exp. Bot. 2019, 165, 391-414. [CrossRef]

55. Ashraf, M.H.P.J.C.; Harris, P.J. Photosynthesis under stressful environments: An overview. Photosynthetica 2013, 51, 163-190. [CrossRef]

56. Tsimilli-Michael, M. Special issue in honour of Prof. Reto J. Strasser-Revisiting JIP-test: An educative review on concepts, assumptions, approximations, definitions and terminology. Photosynthetica 2020, 58, $275-292$. [CrossRef]

57. Roháček, K. Chlorophyll fluorescence parameters: The definitions, photosynthetic meaning, and mutual relationships. Photosynthetica 2002, 40, 13-29. [CrossRef]

58. Baker, N.R.; Rosenqvist, E. Applications of chlorophyll fluorescence can improve crop production strategies: An examination of future possibilities. J. Exp. Bot. 2004, 55, 1607-1621. [CrossRef]

59. Kalaji, H.M.; Rastogi, A.; Živčák, M.; Brestic, M.; Daszkowska-Golec, A.; Sitko, K.; Alsharafa, K.Y.; Lotfi, R.; Stypiński, P.; Samborska, I.A.; et al. Prompt chlorophyll fluorescence as a tool for crop phenotyping: An example of barley landraces exposed to various abiotic stress factors. Photosynthetica 2018, 56, 953-961. [CrossRef]

(C) 2020 by the authors. Licensee MDPI, Basel, Switzerland. This article is an open access article distributed under the terms and conditions of the Creative Commons Attribution (CC BY) license (http://creativecommons.org/licenses/by/4.0/). 